\title{
Stability of the exact solutions describing the two-layer flows with evaporation at interface
}

\author{
V.B. Bekezhanova ${ }^{1,2} \ddagger$ and O.N. Goncharova ${ }^{3,4} \S$ \\ ${ }^{1}$ Institute of Computational Modelling SB RAS, Akademgorodok, 50/44, \\ Krasnoyarsk, 660036, RUSSIA \\ ${ }^{2}$ Institute of Mathematics and Computer Science, Siberian Federal University, \\ Svobodny, 79, Krasnoyarsk, 660041, RUSSIA \\ ${ }^{3}$ Altai State University, Lenina 61, Barnaul, 656049, RUSSIA \\ ${ }^{4}$ Institute of Thermophysics, SB RAS, Lavrentyev, 1, Novosibirsk, 630090, RUSSIA
}

\begin{abstract}
A new exact solution of the equations of free convection has been constructed in the framework of the Oberbeck-Boussinesq approximation of the Navier-Stokes equations. The solution describes a joint flow of an evaporating viscous heat-conducting liquid and gas-vapor mixture in the horizontal channel. In the gas phase the Dufour and Soret effects are taken into account. The consideration of the exact solution allows one to describe different classes of flows depending on the values of the problem parameters and boundary conditions for the vapor concentration. A classification of solutions and results of the solution analysis have been presented.

The effects of the external disturbing influences (of the liquid flow rates and longitudinal gradients of temperature on the channel walls) on the stability characteristics have been numerically studied for the system HFE7100-nitrogen in the common case, when the longitudinal temperature gradients on the boundaries of the channel are not equal.

In the system both monotonic and oscillatory modes can be formed, which damp or grow depending on the values of the initial perturbations, flow rates and temperature gradients. Hydrodynamic perturbations are the most dangerous under large gas flow rates. The increasing oscillatory perturbations are developed due to the thermocapillary effect under large longitudinal gradients of temperature. The typical forms of the disturbances are shown.
\end{abstract}

Keywords: Two-layer flow, thermocapillary interface, exact solution, finite amplitude perturbations

$\ddagger$ Corresponding author: bekezhanova@mail.ru

$\S$ Corresponding author: gon@math.asu.ru 


\section{Introduction}

At present advanced technologies and experimental investigation methods of the features of joint convective liquid flows and cocurrent gas fluxes at normal and microgravity have actively been developed. The improvement of the existing techniques and development of new experiments are based, in many ways, on theoretical results obtained using the mathematical modeling of two-layer flows with interfaces. The media flow rates, their thermophysical properties, type of a thermal load on the flow domain boundaries and linear scales influence the character of the convective flows (Lyulin and Kabov 2013, 2014). The high accuracy of the experimental measurements of different thermodynamic properties of a fluid allows one to study the velocity fields near the interface, to define the dominant character of various factors and to compare the experimental and theoretical results.

Two-layer flows can be used for thermostabilization and liquid cooling of electronic devices. The efficiency of heat pipes, film (membrane) evaporators, two-phase cooling systems depends on the velocity of the evaporation from the free surface. In practice, the investigation results of the two-layer flows with evaporation can be used in developing a compact high-performance cooling system of electronic equipment and in the drying process, coating application technologies and in distillers. Precisely forecasting the fluid dynamics in thin layers requires the comprehensive analysis based on modeling the twolayers flows with evaporation. It is important for the identification of the mechanisms of possible critical phenomena.

Mathematical models to investigate the convective flows with the mass transfer at the interface require a correct formulation of the boundary conditions. The conditions at the interface are deduced on the basis of some hypotheses on the interface and physical processes, which guarantee the fulfillment of the conservation laws (Prosperetti 1979, Margerit et al 2003, Das and Ward 2007, Kuznetsov 2010, Frezzotti 2011, Kuznetsov 2011, Goncharova 2012a). The convective flows accompanied by evaporation or condensation at the interface were studied in (Oron et al 1997, Shklyaev and Fried 2007, Kuznetsov and Andreev 2013, Kabova et al 2014, Goncharova and Rezanova 2014a, Goncharova et al 2014c, Goncharova and Rezanova 2015c) analytically and numerically using the mathematical models constructed based on the long-wave approach of the governing equations and boundary conditions. Mathematical models based on the Navier-Stokes equations and relations at the interface, which generalize the dynamic, heat and kinematic conditions allow one to obtain the results being in agreement with the experiments of convection under the heat- and mass transfer through the interface (Iorio et al 2007, Celata et al 2008, Lyulin and Kabov 2013, 2014). Similar problems of the convective flows with evaporation are studied in (Iorio et al 2009, 2011) in the full statements of the problem.

Recently special attention has been paid to the construction and investigation of an exact solution describing the convective flow and taking into account the mass transfer 
at the interface, in particular, due to evaporation. The analysis of the properties of the exact solutions allows one to investigate the effects of different factors on the flow topology, evaporation intensity at the interface and stability characteristics of the basic flow. The theoretical results provide an opportunity to predict a possible outcome of the experiments (Iorio et al 2007, Celata et al 2008, Lyulin and Kabov 2013, 2014, Lyulin et al 2015) and to create fundamentally new practical techniques. One of the first exact solutions describing the flows in the two-layer systems with the mass transfer was presented in (Shliomis and Yakushin 1972) for a "fluid-fluid" system. The papers (Goncharova et al 2013, Goncharova and Rezanova 2014b) present an exact solution for studying the two-layer flow with evaporation at the thermocapillary interface in a "fluid-gas" system and with the Dufour effect in the gas phase. The solutions studied in (Goncharova et al 2013) satisfy the additional condition of a closed flow, whereas in (Goncharova and Rezanova 2014b) the exact solution of the stationary problem for the given gas flow rate were obtained. A comparison of the analytical results obtained with the help of the above mentioned exact solutions with the experimental ones was made in (Goncharova et al 2015b).

It is necessary to ensure the stability of the basic state of the working fluid in the experiments and equipment using the fluid technology where evaporation is significant. If to take into consideration the expenses on the experiments, then one of the most important aspects of the preliminary theoretical investigation is the identification and analysis of the conditions ensuring the stability. The main part of the studies concerns the problem of the stability of thin liquid films which are most sensitive to evaporation, and stability of the liquid equilibrium (Burelbach et al 1988, Oron 2000, Sultan et al 2005, Shklyaev and Fried 2007, Klentzman and Ajaev 2009, Liu and Kabov 2012).

In the present paper the exact solutions of the Oberbeck-Boussinesq equations describing the two-layer fluid flows in a horizontal layer are investigated. In the basic equations the effects of thermodiffusion and diffusive heat conductivity are additionally taken into consideration. The analysis of the flow characteristics formed under the influence of inhomogeneous factors allows one to understand the physical mechanisms of the studied processes and to estimate the degree of the interaction of several effects. The properties of the periodic finite-amplitude perturbations of the main flow and the effects of the problem parameters on their structure and mechanisms leading to the change of the flow patterns are investigated.

The aim of the paper is to perform the analysis of the exact solutions of the equations of natural convection as well as to analyze the influence of the type of the boundary conditions for the vapor concentration, and the physical effects on the solution properties and to define the typical forms of the arising perturbations at an example of one of the constructed solutions. 


\section{Basic assumptions and statement of the problem}

Let a liquid and a gas-vapor mixture fill an infinite horizontal channel with solid impermeable immovable upper $y=h_{2}$ and lower $y=-h_{1}$ walls. The coordinate system is chosen so that the gravity vector has the coordinates $\mathbf{g}=(0,-g)$ (figure 1$)$. The thermocapillary interface $\Gamma$ remains to be undeformed during the motion and it is given by $y=0$. The tangential forces act along $\Gamma$ and the surface tension $\sigma$ depends linearly on the temperature $\sigma=\sigma_{0}+æ\left(T-T_{0}\right)$, where $æ<0$, $æ$ is the temperature coefficient of the surface tension, $T_{0}$ is an initial temperature value. In addition, the mass transfer due to evaporation is taken into account at the interface.

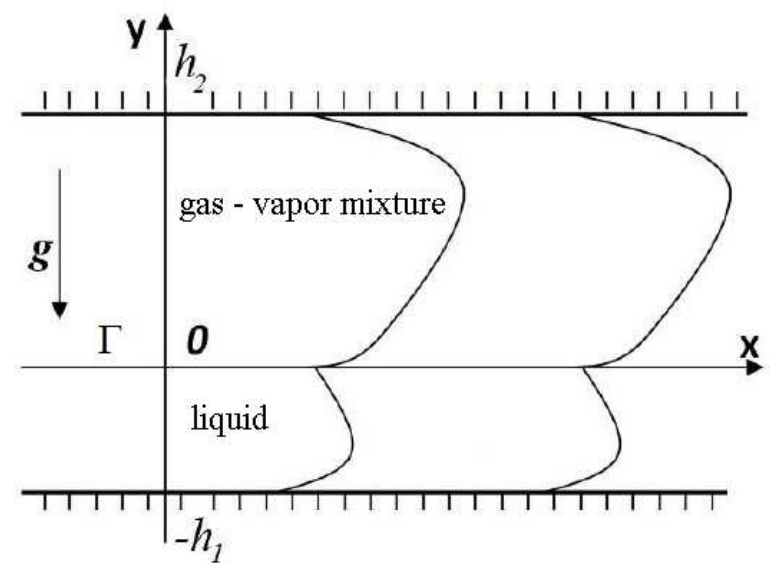

Figure 1. Flow region.

\subsection{Governing equations}

The flow in a two-phase system is described by the Oberbeck - Boussinesq approximation of the Navier-Stokes Equations, including the terms which correspond to the Dufour and Soret effects (De Groot 1956, Gebhart et al 1988, Andreev et al 2012, Andreev and Sobachkina 2012, Ryzhkov 2013) in the upper layer (see Goncharova et al 2015b). The Dufour effect is the appearance of the temperature gradient due to the presence of the concentration gradient. It is well known that this effect can reach a few degrees of Celsius in gases and less than a thousandth in fluids (De Groot 1956, De Groot and Mazur 1962). In the monographs (De Groot and Mazur 1962, Gebhart at al 1988) the importance of taking into consideration the effects of diffusive heat conductivity was emphasized. The influence of the Soret effect on the fluid flows was considered in (Andreev et al 2012).

The equations of the motion and heat transfer have the form

$$
\frac{\partial u}{\partial t}+u \frac{\partial u}{\partial x}+v \frac{\partial u}{\partial y}=-\frac{1}{\rho} \frac{\partial p}{\partial x}+\nu\left(\frac{\partial^{2} u}{\partial x^{2}}+\frac{\partial^{2} u}{\partial y^{2}}\right)
$$




$$
\begin{aligned}
& \frac{\partial v}{\partial t}+u \frac{\partial v}{\partial x}+v \frac{\partial v}{\partial y}=-\frac{1}{\rho} \frac{\partial p}{\partial y}+\nu\left(\frac{\partial^{2} v}{\partial x^{2}}+\frac{\partial^{2} v}{\partial y^{2}}\right)+g\left(\beta T+\underline{\gamma C_{s}}\right), \\
& \frac{\partial u}{\partial x}+\frac{\partial v}{\partial y}=0 \\
& \frac{\partial T}{\partial t}+u \frac{\partial T}{\partial x}+v \frac{\partial T}{\partial y}=\chi\left[\frac{\partial^{2} T}{\partial x^{2}}+\frac{\partial^{2} T}{\partial y^{2}}+\delta\left(\frac{\partial^{2} C_{s}}{\partial x^{2}}+\frac{\partial^{2} C_{s}}{\partial y^{2}}\right)\right] .
\end{aligned}
$$

The vapor is a passive admixture. The vapor diffusion in the gas is described by the equation

$$
\frac{\partial C_{s}}{\partial t}+u \frac{\partial C_{s}}{\partial x}+v \frac{\partial C_{s}}{\partial y}=D\left[\frac{\partial^{2} C_{s}}{\partial x^{2}}+\frac{\partial^{2} C_{s}}{\partial y^{2}}+\alpha\left(\frac{\partial^{2} T}{\partial x^{2}}+\frac{\partial^{2} T}{\partial y^{2}}\right)\right],
$$

which is a result of the Fick law. The Fick laws were consistently confirmed by experiment (Umov 1950) in the studies of low concentration solutions (Putilov 1963). In Putilov's monograph the comprehensive substantiation of the formal equivalence of the Maxwell's formulae (Maxwell 1890) for the vapor concentration and the Fick's equation is provided as well as additional ideas concerning the peculiarities of their use are also presented. These laws are also valid for the interdiffusion of various gases (Sivukhin 2005).

The underlined terms in (2), (4) and equation (5) are taken into account in modeling of the gas-vapor mixture flow in the upper layer. Here, $u, v$ are the projection of the velocity vector on the axes $O x$ and $O y$, respectively, $p$ is the modified pressure, the deviation from the hydrostatic one, $T$ is the temperature, $C_{s}$ is the vapor concentration. The physical characteristics of the media $\rho, \nu, \chi, D, \beta, \gamma$ (density, coefficients of kinematic viscosity, heat diffusivity, vapor diffusion in the gas, heat- and concentration expansion, respectively) are constant. The coefficients $\delta$ and $\alpha$ characterize the Dufour and Soret effects (Gebhart et al 1988, De Groot 1956). The Soret effect has been studied well enough, including the experimental investigations of the Soret coefficients for some media (see, for instance, (Mialdun and Shevtsova 2011)). According to (De Groot and Mazur 1962; Gebhart et al 1988) the coefficients $\delta$ and $\alpha$ in the gases take on values of the orders $\delta \sim 10^{-6}-10^{-4} \mathrm{~K}, \alpha \sim 10^{-5}-10^{-3} \mathrm{~K}^{-1}$.

In general, the Soret and Dufour coefficients depend on physical parameters of the gas-liquid systems, on temperature and concentration of the mixture components. In our paper, as in the cited monographs (Andreev et al 2012, Andreev and Sobachkina 2012, Ryzhkov 2013), these coefficients are assumed to be constant. This assumption is valid under moderate drops of temperature and concentration.

\subsection{Form of the exact solution}

According to (Napolitano 1980, Goncharova and Rezanova 2014b) the system of equations (1)-(5) admits the stationary solution

$$
u_{j}=u_{j}(y), \quad v_{j}=0, \quad p_{j}=p_{j}(x, y),
$$




$$
T_{j}=\left(a_{1}^{j}+a_{2}^{j} y\right) x+\vartheta_{j}(y), \quad C_{s}=\left(b_{1}+b_{2} y\right) x+\phi(y)
$$

where the variables and parameters with the index $j=1,2$ (subscript or superscript) relate to the phases filling the lower and upper layers, respectively. The solution (6) is a generalization of the well known Ostroumov-Birikh solution (Ostroumov 1952, Birikh 1966), which describes the unidirectional convective flow in the horizontal layer. The group nature of the solution (6) and its possible generalizations in the three-dimensional case were systematically studied in (Pukhnachev 2000).

Substitution of (6) into the system (1)-(5) leads to the following polynomial relations:

$$
\begin{aligned}
& u_{j}(y)=L_{4}^{j} y^{4}+L_{3}^{j} y^{3}+c_{1}^{j} y^{2}+c_{2}^{j} y+c_{3}^{j}, \\
& T_{j}(x, y)=\left(a_{1}^{j}+a_{2}^{j} y\right) x+N_{7}^{j} y^{7}+N_{6}^{j} y^{6}+N_{5}^{j} y^{5}+ \\
& +N_{4}^{j} y^{4}+N_{3}^{j} y^{3}+N_{2}^{j} y^{2}+c_{4}^{j} y+c_{5}^{j}, \\
& p_{j}(x, y)=\left(d_{1}^{j}+d_{2}^{j} y+d_{3}^{j} y^{2}\right) x+K_{8}^{j} y^{8}+K_{7}^{j} y^{7}+K_{6}^{j} y^{6}+ \\
& +K_{5}^{j} y^{5}+K_{4}^{j} y^{4}+K_{3}^{j} y^{3}+K_{2}^{j} y^{2}+K_{1}^{j} y+c_{6}^{j}, \\
& C_{s}(x, y)=\left(b_{1}+b_{2} y\right) x+S_{7} y^{7}+S_{6} y^{6}+S_{5} y^{5}+S_{4} y^{4}+S_{3} y^{3}+ \\
& +S_{2} y^{2}+c_{7} y+c_{8} .
\end{aligned}
$$

Note that some coefficients of the polynomials (7) depend on the Dufour and Soret parameters. The evaporation intensity also depends on these parameters.

The coefficients $c_{m}^{j}(m=1, . ., 6), c_{7}, c_{8}$ are the integration constants, $L_{4}^{j}, L_{3}^{j}, N_{i}^{j}$, $K_{m}^{j}, S_{i}(i=2, . ., 7, m=1, . ., 8)$ and $d_{i}^{j}(i=1,2,3)$ in the polynomials $(7)$ are expressed in terms of the physical parameters of the problem such as $\nu, \chi, \rho, D, \beta, \gamma, g$, longitudinal temperature and concentration gradients $a_{i}^{j}, b_{j}(i=1,2)$, and integration constants. The boundary conditions would impose possible relations between $a_{i}^{j}$ and $b_{j}$ and allow one to calculate the integration constants $c_{m}^{j}, c_{7}, c_{8}$.

\subsection{Boundary conditions}

At the boundaries of the channel $y=-h_{1}$ and $y=h_{2}$ the no-slip conditions

$$
u_{1}\left(-h_{1}\right)=0, \quad u_{2}\left(h_{2}\right)=0,
$$

and the linear temperature distribution with respect to the longitudinal coordinate

$$
T_{1}\left(x,-h_{1}\right)=A_{1} x+T_{10}, \quad T_{2}\left(x, h_{2}\right)=A_{2} x+T_{20}
$$

are to be valid. The constants $A_{1}, A_{2}, T_{10}, T_{20}$ are taken to be known.

Two types of the conditions for the vapor concentration $C_{s}$ can be considered. Assume that the condition of the absence of the vapor flux at the upper boundary $y=h_{2}$ is satisfied

$$
\left.\frac{\partial C_{s}}{\partial y}\right|_{y=h_{2}}=0
$$


Instead of (10) the boundary condition of the zero vapor concentration can be set on $y=h_{2}$

$$
\left.C_{s}\right|_{y=h_{2}}=0
$$

It is interpreted as a condition characterizing the property of the upper boundary to instantly absorb the vapor or as a condition defining the condensation (Goncharova et al 2013, Goncharova et al 2015b). In the last case a crucial question is an assumption on a constant character of the concentration at the solid boundary instead of taking into account its temperature dependence. However, we consider condition (11) to be physically plausible in the moderate temperature range.

At the interface $y=0$ the kinematic and dynamic conditions should be satisfied. Since the mass transfer is not considered in the kinematic condition, this condition holds automatically due to the form of the exact solution (6). The projections of the dynamic condition on the tangential and normal vectors to the interface can be written as follows (Andreev et al 2012, Goncharova and Rezanova 2014b):

$$
p_{1}=p_{2}, \quad \rho_{1} \nu_{1} \frac{d u_{1}}{d y}=\rho_{2} \nu_{2} \frac{d u_{2}}{d y}+x \frac{\partial T}{\partial x} .
$$

The conditions of continuity of the longitudinal velocities and temperature are also imposed at the interface

$$
u_{1}=u_{2}, \quad T_{1}=T_{2} .
$$

Because of the last relation the equality of the coefficients $a_{1}^{1}=a_{1}^{2}=A$ should hold.

The heat transfer condition with the diffusive-type evaporation at the interface $y=0$ has the form (Andreev et al 2012, Goncharova and Rezanova 2014b)

$$
k_{1} \frac{\partial T_{1}}{\partial y}-k_{2} \frac{\partial T_{2}}{\partial y}-\left.\delta k_{2} \frac{\partial C_{s}}{\partial y}\right|_{y=0}=-L M
$$

Here, $L$ is the latent heat of evaporation, $M$ is the evaporation mass flow rate, $k_{1}, k_{2}$ are the heat conductivity coefficients. The evaporation effects are taken into account only in the heat transfer condition at the interface. The convective mass transfer is not considered; only the diffusive mass flux at the interface is assumed. The heat consumption for vaporization is taken into consideration in the heat balance condition (Shliomis and Yakushin 1972, Kuznetsov 2010). The evaporation mass flow rate should satisfy the expression of the mass balance at the interface, including the Soret effect in the gas phase:

$$
M=-D \rho_{2}\left(\left.\frac{\partial C_{s}}{\partial y}\right|_{y=0}+\left.\alpha \frac{\partial T_{2}}{\partial y}\right|_{y=0}\right) .
$$

The condition (15) is single out for computational convenience and for determination of a relationship between the thermal and mass balance conditions at interface. At the same time, in calculations it allows one to show $M$ that is an additional quantitative characteristic of the flow and is interesting for comparison with experiments. The form of the solution allows one to realize the case of linear dependence of $M$ on 
the longitudinal coordinate. However, in constructing the solution we realize exactly the case with the constant evaporation mass flow rate $M$. An interest to this situation has been dictated by comparison of the quantitative flow characteristics obtained in the experiments (Goncharova et al 2015b). At present the experimental data are presented as the trendlines (Lyulin and Kabov 2013, 2014).

In the case when the upper layer of the system is filled by a one-component medium, the concentration of the admixture (of vapor) in the liquid is taken to be equal to 1 . The saturated vapor should be above the surface of such a liquid (Shliomis and Yakushin 1972). The saturated vapor concentration is found using the relation

$$
\left.C_{s}\right|_{y=0}=C_{*}\left[1+\varepsilon\left(\left.T_{2}\right|_{y=0}-T_{0}\right)\right]
$$

that is a consequence of the Clapeyron-Clausius equation $P=P_{0} \exp \left[\left(L \mu_{0} / R^{*}\right)\left(1 / T_{0}-\right.\right.$ $-1 / T)$ ] and the Mendeleev - Clapeyron equation for an ideal gas $\rho_{v} R T=\mu_{0} P$. A similar approach to derive the relation for the vapor concentration at the interface was used in (Ghezzehei et al 2004, see also Shliomis and Yakushin 1972, Gatapova and Kabov 2008). Here, $P_{0}, T_{0}$ are the functions describing some initial state, $R^{*}$ is the universal gas constant, $\mu_{0}$ is the molar mass of the evaporating liquid, $\varepsilon=L \mu_{0} /\left(R^{*} T_{0}^{2}\right), C_{*}$ is the saturated vapor concentration at $T_{2}=T_{0}$ ( $T_{0}$ is equal to $20^{\circ}$ in (Shliomis and Yakushin 1972, Goncharova and Rezanova 2014b)), $\rho_{v}=C \rho_{2}$. If $C_{s}=1$ in the liquid layer and the exact balance condition of the vapor mass is considered, then the value of the mass rate of evaporation will be determined as follows (Nakoryakov et al 2003, Haut and Colinet 2005, Gatapova and Kabov 2008, Kuznetsov 2010, Goncharova 2012a):

$$
M=-\frac{D \rho_{2}}{1-C_{s}}\left(\frac{\partial C_{s}}{\partial n}+\alpha \frac{\partial T_{2}}{\partial n}\right) .
$$

Equation (16) is obtained, given the smallness of the parameter $\left(\varepsilon T_{*}\right)$ for moderate temperature variations (Goncharova et al 2103, Goncharova and Rezanova 2014b). Here, $T_{*}$ is the typical value of a temperature drop. Note that the exact mass balance relation requires using the coefficient $D_{*}$ equal to the diffusion coefficient divided by $\left(1-C_{s}\right.$ ) instead of $D$ in (15) (Nakoryakov et al 2003, Haut and Colinet 2005, Gatapova and Kabov 2008, Goncharova 2012a). According to the previous assumptions on the moderate values of the temperature and its variations the condition of smallness of the parameter $\left(C_{*} \varepsilon T_{*}\right)$ is valid so that we can make a conclusion that $D_{*}=D /\left(1-C_{*}\right)$.

The influence of the Soret and Dufour effects on the evaporation velocity was investigated in (Maciev and Stasenko 1987, Maciev et al 1987).

The relation should be included into the problem statement, which determines the mass flow rate of the gas $R$ in the upper layer:

$$
R=\int_{0}^{h_{2}} \rho_{2} u_{2}(y) d y .
$$

In the strict sense, solution (6) can not be called an exact one and applied for studying real fluid flows, in particular, because of the infinite domain of the flow. But this was confirmed in experimental and numerical studies by Kirdyashkin A.G. and 
co-authors (see, for example, Kurdyashkin et al. 1983) for the channel with the finite length. The flows, which can be described by the solution, are unidirectional ones and they are realized in experiments investigating the properties of the convective flows with evaporation (Lyulin and Kabov 2013, 2014, Lyulin et al 2015).

An analytical study of the presented exact solutions allows one to estimate the degree of the influence of different factors on the flow character and evaporation dynamics and also, to forecast the experimental results.

\section{Analysis of the exact solution. Classes of flows}

\subsection{Analysis of taking into account the Soret effect in mathematical modeling}

The solution given by (6) seems to be simple, but the construction of the solution requires a carefully elaborated algorithm of finding the integration constants (see (7)). In order to find the constants it should be specified what problem parameters are given. An assumption should be made defining the physically correctly given parameters of the problem.

The investigation of the exact solutions (6) in the case with the constant evaporation mass flow rate $M$ allows one to estimate the extent of the influence of various effects on the flow character, including the Soret and Dufour effects. The degree of the influence is found to depend on the type of the boundary condition for the vapor concentration on the upper solid wall $y=h_{2}$. Let the vapor concentration on this wall be equal to zero (the condition of vapor absorption (11)). In this case a relation is established between the coefficients $A, A_{1}$ and $A_{2}$. The coefficients define the longitudinal temperature gradients which should be maintained on the channel boundaries (see, for example, Goncharova et al 2015b). The given thermal conditions on the solid walls (9) are imposed by the form of the exact solutions. Other types of the conditions for the temperature on the solid boundaries can also be satisfied (Goncharova 2015a).

If one of the temperature gradients on the channel boundary, for example, $A_{1}$, is set, then the values of other longitudinal gradients are determined:

$$
A=\frac{\alpha A_{1}}{\alpha+\frac{h_{1}}{h_{2}} \frac{k_{2}}{k_{1}} C_{*} \varepsilon(\alpha \delta-1)}, \quad A_{2}=\frac{A_{1}\left(\alpha+C_{*} \varepsilon\right)}{\alpha+\frac{h_{1}}{h_{2}} \frac{k_{2}}{k_{1}} C_{*} \varepsilon(\alpha \delta-1)} .
$$

If the Soret effect is not taken into consideration $(\alpha=0)$, then the temperature gradient along the interface should be taken to be equal to zero $A=0$. Thus, modeling of the thermocapillary convection will be impossible in this case. Upon specifying one temperature gradient on the solid boundaries, for example, $A_{1}$ as earlier, one obtains another gradient $A_{2}$ based on the heat transfer condition:

$$
A_{2}=-A_{1} \frac{h_{2}}{h_{1}} \frac{k_{1}}{k_{2}} \text {. }
$$

The exact solution (6) imposes the peculiar compatibility conditions between the coefficients defining the longitudinal temperature gradients $A, A_{1}$ and $A_{2}$, and concentrations $b_{1}, b_{2}$. 
Let condition (10) be imposed on the boundary $y=h_{2}$, which is usually used in the investigations of the problems with the evaporation at the interface (Gatapova and Kabov 2008, Nakoryakov et al 2003, Goncharova and Rezanova 2014b). If the Soret effect is taken into account, then the equality of all the longitudinal temperature gradients $A=A_{1}=A_{2}$ should hold. If the Soret effect is neglected in the mathematical modeling of the two-layer flows using the exact solution (6), then two of the three temperature gradients on the boundaries $y=0, y=-h_{1}, y=h_{2}$ can be given, for example, $A$ and $A_{1}$, but the value of the third temperature gradient should be in agreement with the known values:

$$
A_{2}=A+\left(A-A_{1}\right) \frac{h_{2}}{h_{1}} \frac{k_{1}}{k_{2}} .
$$

If $A, A_{1}, A_{2}$ are known, then $a_{2}^{1}$ and $a_{2}^{2}$ (see (6)) can be calculated.

The analysis results of the Soret effect on the peculiarities of the fluid flows connected with modeling the thermal boundary regimes are presented in Table 1 . The analysis of the constructed solutions shows the impact of the thermodiffusion effect (the Soret effect) not only on the temperature and vapor concentration profiles and values of the mass rate of evaporation, but also on the velocity profile.

Let $\left(u_{j}(\alpha, y), T_{j}(\alpha, y), p_{j}(\alpha, y), C_{s}(\alpha, y)\right)$ denote solution (7) of equations (1) (5) constructed taking into account the Soret effect $(\alpha \neq 0)$. Let also $\left(u_{j}(0, y)\right.$, $\left.T_{j}(0, y), p_{j}(0, y), C_{s}(0, y)\right)$ be the solution (7) of equations (1) - (5) without taking into consideration the thermodiffusion effect in the upper layer, which are written at $\alpha=0$. The limiting transition $\left(u_{j}(\alpha, y), T_{j}(\alpha, y), p_{j}(\alpha, y), C_{s}(\alpha, y)\right) \rightarrow\left(u_{j}(0, y)\right.$, $\left.T_{j}(0, y), p_{j}(0, y), C_{s}(0, y)\right)$ takes place at $\alpha \rightarrow 0$.

The algorithms for determining the integration constants for some boundary value problems are described in detail in (Goncharova and Rezanova 2014b, Goncharova et al 2015b).

The exact form of the coefficients $L_{4}^{j}, L_{3}^{j}, N_{i}^{j}, K_{m}^{j}, S_{i}(i=2, . ., 7, m=1, . ., 8)$ and $d_{i}^{j}(i=1,2,3)$ can be found in (Goncharova et al 2016).

\subsection{Classes of flows}

The solutions of special type (6) were constructed and studied in (Goncharova et al 2013) to investigate the two-layer fluid flows with evaporation which are subject to the Dufour effect in the gas phase and under additional conditions implying the closeness of the flows in both liquid and gas-vapor phases. Under the condition of the given gas flow rate (17) a solution was constructed in (Goncharova and Rezanova 2014b, Goncharova et al 2015b); the solution describes the flows with evaporation at the interface, if conditions (10) (see (Goncharova and Rezanova 2014b)) and (11) (see (Goncharova et al 2015b)) are satisfied in the upper solid boundary. In (Goncharova et al 2015b) the results of mathematical modeling of the two-layer flows are presented with and without the Soret and Dufour effects in the upper layer. In the same paper the examples of the velocity and temperature profiles are presented for the system "HF7100-nitrogen" with 
Table 1. Analytical investigation results of the Soret effect on the fluid flow features under constant evaporation mass flow rate $M$, depending on the temperature regime and vapor concentration on the boundaries

\begin{tabular}{|c|c|c|c|c|}
\hline & $\begin{array}{l}\text { Flow 1: Condition of } \\
\text { the zero vapor concen- } \\
\text { tration }(11) \text { and tak- } \\
\text { ing into account the } \\
\text { Soret effect }(\alpha \neq 0)\end{array}$ & $\begin{array}{l}\text { Flow 2: Condi- } \\
\text { tion of the zero } \\
\text { vapor concentra- } \\
\text { tion }(11) \text { with- } \\
\text { out considering } \\
\text { the Soret effect } \\
(\alpha=0)\end{array}$ & $\begin{array}{l}\text { Flow 3: Con- } \\
\text { dition of the va- } \\
\text { por flux absence } \\
(10) \text { and taking } \\
\text { into account the } \\
\text { Soret effect ( } \alpha \neq \\
0)\end{array}$ & $\begin{array}{l}\text { Flow 4: Condi- } \\
\text { tion of the vapor } \\
\text { flux absence }(10) \\
\text { without consid- } \\
\text { ering the Soret } \\
\text { effect }(\alpha=0)\end{array}$ \\
\hline$A$ & $\begin{array}{l}\text { calculated: } A= \\
\alpha A_{1} \\
\alpha+\frac{h_{1}}{h_{2}} \frac{k_{2}}{k_{1}} C_{*} \varepsilon(\alpha \delta-1)\end{array}$ & $\begin{array}{l}\mathrm{A}=0 \quad(A= \\
\left.=\frac{b_{1}}{C_{*} \varepsilon}\right)\end{array}$ & $\begin{array}{l}A=A_{1}=A_{2} \\
\text { (given) }\end{array}$ & given \\
\hline$A_{1}$ & given & given & $\begin{array}{l}A=A_{1}=A_{2} \\
\text { (given) }\end{array}$ & given \\
\hline$A_{2}$ & $\begin{array}{l}\text { calculated: } A_{2}= \\
\frac{A_{1}\left(\alpha+C_{*} \varepsilon\right)}{\alpha+\frac{h_{1}}{h_{2}} \frac{k_{2}}{k_{1}} C_{*} \varepsilon(\alpha \delta-1)}\end{array}$ & $\begin{array}{l}\text { calculated: } \\
A_{2}=-A_{1} \frac{h_{2}}{h_{1}} \frac{k_{1}}{k_{2}} \\
\text { (consequence of } \\
\text { the heat transfer } \\
\text { condition) }\end{array}$ & $\begin{array}{l}A=A_{1}=A_{2} \\
\text { (given) }\end{array}$ & $\begin{array}{l}\text { calculated: } \\
A_{2}=A+(A- \\
\left.-A_{1}\right) \frac{h_{2}}{h_{1}} \frac{k_{1}}{k_{2}}\end{array}$ \\
\hline$b_{1}$ & $\begin{array}{l}b_{1}=C_{*} \varepsilon A \quad\left(b_{1}=\right. \\
\left.=-b_{2} h_{2}\right)\end{array}$ & $\begin{array}{l}b_{1}=0 \quad\left(b_{1}=\right. \\
\left.=-b_{2} h_{2}\right)\end{array}$ & $b_{1}=C_{*} \varepsilon A$ & $b_{1}=C_{*} \varepsilon A$ \\
\hline$b_{2}$ & $b_{2}=-\frac{C_{*}^{\prime} \varepsilon A}{h_{2}}$ & $\begin{array}{l}b_{2}=0 \quad\left(b_{2}=\right. \\
=-\alpha \frac{A_{2}-A}{h_{2}} ; \\
\text { consequence of } \\
\text { the mass balance } \\
\text { condition) }\end{array}$ & $\begin{array}{l}b_{2}=0 \quad\left(b_{2}=\right. \\
\left.=-\alpha \frac{A_{2}-A}{h_{2}}\right)\end{array}$ & $b_{2}=0$ \\
\hline
\end{tabular}

different values of the gas flow rates and longitudinal temperature gradients $A, A_{j}$. The analytical and experimental results of the liquid evaporation at the thermocapillary interface are compared in (Goncharova et al 2015b); the qualitative, and in some cases, the approximate quantitative coincidence of the results was found.

The key novelty of the present work is the detailed analysis of the exact solution (6), depending on the inclusion/exception of the Soret effect and the boundary condition type for the vapor concentration function. We have also explained the limiting transition from the presented solution with the Soret effect into the earlier studied solution without this effect. This problem is not so evident because of the consideration of the possibility to control the flows (the types of the flow patterns) relative to the thermal boundary 
regimes and, at the same time, relative to the possibility of determining the interface as a thermocapillary boundary. And finally, we suggest some classification of flows admitted by the considered exact solution, depending on the boundary condition for the vapor concentration function and value of the Soret parameter (see Table 1).

The structure of the Ostroumov-Birikh solution allows one to describe various types of flows appearing in the two-layer systems (Andreev and Bekezhanova 2010, Sanochkin 1989). The two-phase flow can be controlled if the linear thickness of the working media, values of the longitudinal temperature gradients and gas flow rates change. Furthermore, it is possible to choose such values of controlling actions that the liquid velocity should be equal to zero and the liquid be at rest (see the analysis of the Ostroumov-Birikh solution in the problem on the two-layer flow without evaporation, Andreev and Bekezhanova 2010).

The typical distributions of the velocity, temperature and concentration in the system of media HFE7100 - nitrogen for Flow 4 ( $\alpha=0$ and the condition of the vapor flux absence (10)) under different thermal loads on the outer walls of the channel, gas flow rates and linear sizes are shown in figures 2 and 3 . For all the cases, the gas flow rate $R$, sizes of the layers $h_{j}$, values of the longitudinal temperature gradients $A_{1}, A_{2}$, $A$ and mass velocity of the evaporated/condensated (if $M<0$ ) liquid $M$ are given. The applied values of the physical parameters of the media are presented in Table 2.

According to (Napolitano 1980) we single out the flows with the Poiseuille's velocity profile (figures 2a, 2c, 3a), purely thermocapillary (figures $2 \mathrm{~b}, 3 \mathrm{~b}$ ) and mixed (figure 3c) profiles, depending on dominant effects. In the first case the flows have a structure close to the Poiseuille's distribution (figures 2a, 3a) in each layer. The flows with the return motions near the channel walls in one of the layers (figure 2c) can also be attributed to this flow type. In this case the thermocapillary effect in the liquid phase is suppressed by gravity; however, in one of the layers the reverse flows can be formed in the wall area. The velocity of the return flow increases with increasing the intensity of the thermal load on the channel walls, but the Poiseuille's structure of the velocity distribution is kept. The pressure function has a complex structure and it increases downstream in the medium where the near-wall return flow arises. In the second medium the viscous effects are dominant. These factors result in the formation of these types of the velocity profiles. Similar flows appear also in the analogous problem with the additional condition of the closed flux which defines the appearance of zones of the return flows (Goncharova et al 2013). Furthermore, the near-wall reverse flow is formed if the following conditions are satisfied simultaneously: the non-zero gas flow rate is given, the zero liquid flow rate is set and the temperature gradients on the channel walls have opposite signs (Goncharova and Rezanova 2014b).

The flows with the purely thermocapillary profile are the flows with only return motion in the liquid phase (figures 2b, 3b). These flows appear due to the thermocapillary effect. This type of the velocity distribution arises in the system with small thicknesses or at rather large $A_{j}>0$ (i. e. the walls heated up in the direction 
Table 2. Values of the physical parameters

\begin{tabular}{|l|c|c|}
\hline Parameter & HFE-7100 & Nitrogen \\
\hline Density $\rho, \mathrm{kg} / \mathrm{m}^{3}$ & $1.5 \cdot 10^{3}$ & 1.2 \\
\hline $\begin{array}{l}\text { Kinematic viscosity } \nu, \\
\mathrm{m}^{2} / \mathrm{s}\end{array}$ & $0.38 \cdot 10^{-6}$ & $0.15 \cdot 10^{-4}$ \\
\hline $\begin{array}{l}\text { Thermal expansion coeffi- } \\
\text { cient } \beta, K^{-1}\end{array}$ & $1.8 \cdot 10^{-3}$ & $3.67 \cdot 10^{-3}$ \\
\hline $\begin{array}{l}\text { Temperature coefficient of } \\
\text { the surface tension } \sigma_{T},\end{array}$ & $-1.14 \cdot 10^{-4}$ \\
$\mathrm{~N} /(\mathrm{m} \cdot \mathrm{K})$ & \\
\hline $\begin{array}{l}\text { Diffusion coefficient } D, \\
\mathrm{~m}^{2} / \mathrm{s}\end{array}$ & $0.7 \cdot 10^{-5}$ \\
\hline $\begin{array}{l}\text { Latent heat of evaporation } \\
L,(\mathrm{~W} \cdot \mathrm{s}) / \mathrm{kg}\end{array}$ & \multicolumn{2}{|c|}{$1.11 \cdot 10^{5}$} \\
\hline $\begin{array}{l}\text { Heat conductivity coeffi- } \\
\text { cient } k, \mathrm{~W} /(\mathrm{m} \cdot \mathrm{K})\end{array}$ & 0.07 & 0.02717 \\
\hline $\begin{array}{l}\text { Heat diffusivity coefficient } \\
\chi, \mathrm{m}^{2} / \mathrm{s}\end{array}$ & $0.4 \cdot 10^{-7}$ & $0.3 \cdot 10^{-4}$ \\
\hline $\begin{array}{l}\text { Concentration expansion } \\
\text { coefficient } \gamma\end{array}$ & \multicolumn{2}{|c|}{-0.5} \\
\hline $\begin{array}{l}\text { Saturated vapor concen- } \\
\text { tration } C_{*}\end{array}$ & 0.45 \\
\hline Dufour coefficient $\delta, \mathrm{K}$ & \multicolumn{2}{|c|}{$10^{-5}$} \\
\hline
\end{tabular}

of stream axis) when the fluid moves from the hot pole to the cold one. In this case it is clearly visible that the minimum temperature is reached near the interface due to the presence of the evaporation effects. The flows with the mixed velocity profile are characterized by the velocity "delamination" near the interface, but inside the layers the flow topology is defined by non-zero pressure gradient (figure $3 \mathrm{c}$ ). If $A_{j}, A$ are positive, the reverse flow is formed near $\Gamma$, and if $A_{j}, A$ are negative, the appearance of a "wedge" is due to the co-directional action of the thermocapillary mechanism and shear stresses.

It should be noted that the thickness of the liquid layer does not affect the vapor concentration field which considerably depends on the values of the gas flow rates and temperature gradient.

\section{Non-dimensional variables and parameters}

Thus, the exact solution (6) can describe different types of flows. Further investigations will be carried out for Flow 4 on condition that $T_{20}=T_{10}=20^{\circ} \mathrm{C}$.

We introduce the characteristic values and specify the units of physical parameters for the coupled problem on the basis of the characteristic values for the vapor-gas 

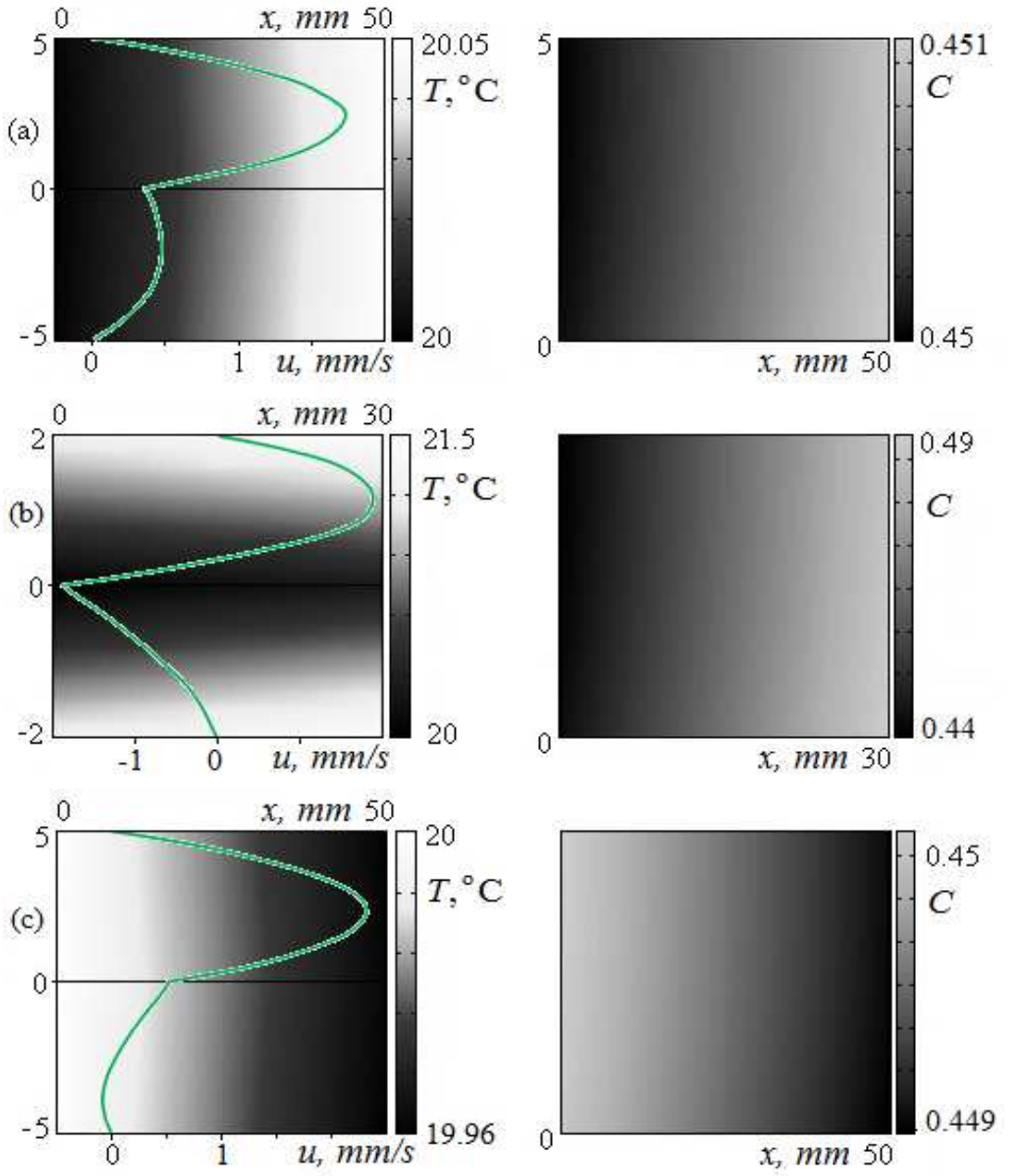

Figure 2. Distributions of the velocity (solid line), temperature (left) and concentration (right) for Flow 4: a) - $h_{1}=h_{2}=5 \mathrm{~mm}, R=9.6 \cdot 10^{-6} \mathrm{~kg} /(\mathrm{m} \cdot \mathrm{s}), A_{1}=5 \mathrm{~K} / \mathrm{m}$, $\left.A_{2}=-10 \mathrm{~K} / \mathrm{m}, A=0.8058 \mathrm{~K} / \mathrm{m}, M=2.054 \cdot 10^{-7} \mathrm{~kg} /\left(\mathrm{m}^{2} \cdot \mathrm{s}\right) ; \mathrm{b}\right)-h_{1}=h_{2}=2 \mathrm{~mm}$, $\left.R=9.6 \cdot 10^{-6} \mathrm{~kg} /(\mathrm{m} \cdot \mathrm{s}), A_{1}=A_{2}=A=30 \mathrm{~K} / \mathrm{m}, M=7.646 \cdot 10^{-6} \mathrm{~kg} /\left(\mathrm{m}^{2} \cdot \mathrm{s}\right) ; \mathrm{c}\right)-$ $h_{1}=h_{2}=5 \mathrm{~mm}, R=9.6 \cdot 10^{-6} \mathrm{~kg} /(\mathrm{m} \cdot \mathrm{s}), A_{1}=-5 \mathrm{~K} / \mathrm{m}, A_{2}=10 \mathrm{~K} / \mathrm{m}, A=-0.8058 \mathrm{~K} / \mathrm{m}$, $M=-2.054 \cdot 10^{-7} \mathrm{~kg} /\left(\mathrm{m}^{2} \cdot \mathrm{s}\right)$.

mixture. Let the linear size of the vapor-gas layer in the $y$-direction $h_{2}$ be the characteristic length, $\nu_{2} / h_{2}, \rho_{2} \nu_{2}^{2} / h_{2}^{2}, T_{20}$ are the characteristic velocity, pressure and temperature, respectively. Non-dimensional variables have the following form: $\eta=x / h_{2}$, $\xi=y / h_{2}, \tau=\nu_{2} t / h_{2}^{2}$. For any parameters of the medium $\omega_{j}$, a non-dimensional analogue $\omega_{j}=\omega_{j} / \omega_{2}$ is introduced. Thus, the domain $-h \leq \xi \leq 0$ corresponds to the index $j=1$ and $0 \leq \xi \leq 1$ corresponds to $j=2$.

The following non-dimensional parameters appear:

$$
\begin{gathered}
\operatorname{Pr}=\frac{\nu_{2}}{\chi_{2}}, \mathrm{Gr}=\frac{g \beta_{2} T_{20} h_{2}^{3}}{\nu_{2}^{2}}, \mathrm{Ma}=\frac{æ A h_{2}^{2}}{\nu_{2}^{2} \rho_{2}}, \\
\mathrm{Ga}=\frac{g h_{2}^{3}}{\nu_{2}^{2}}, \mathrm{Le}=\frac{D}{\chi_{2}}, \mathrm{Q}=\frac{A h_{2}}{T_{20}},
\end{gathered}
$$



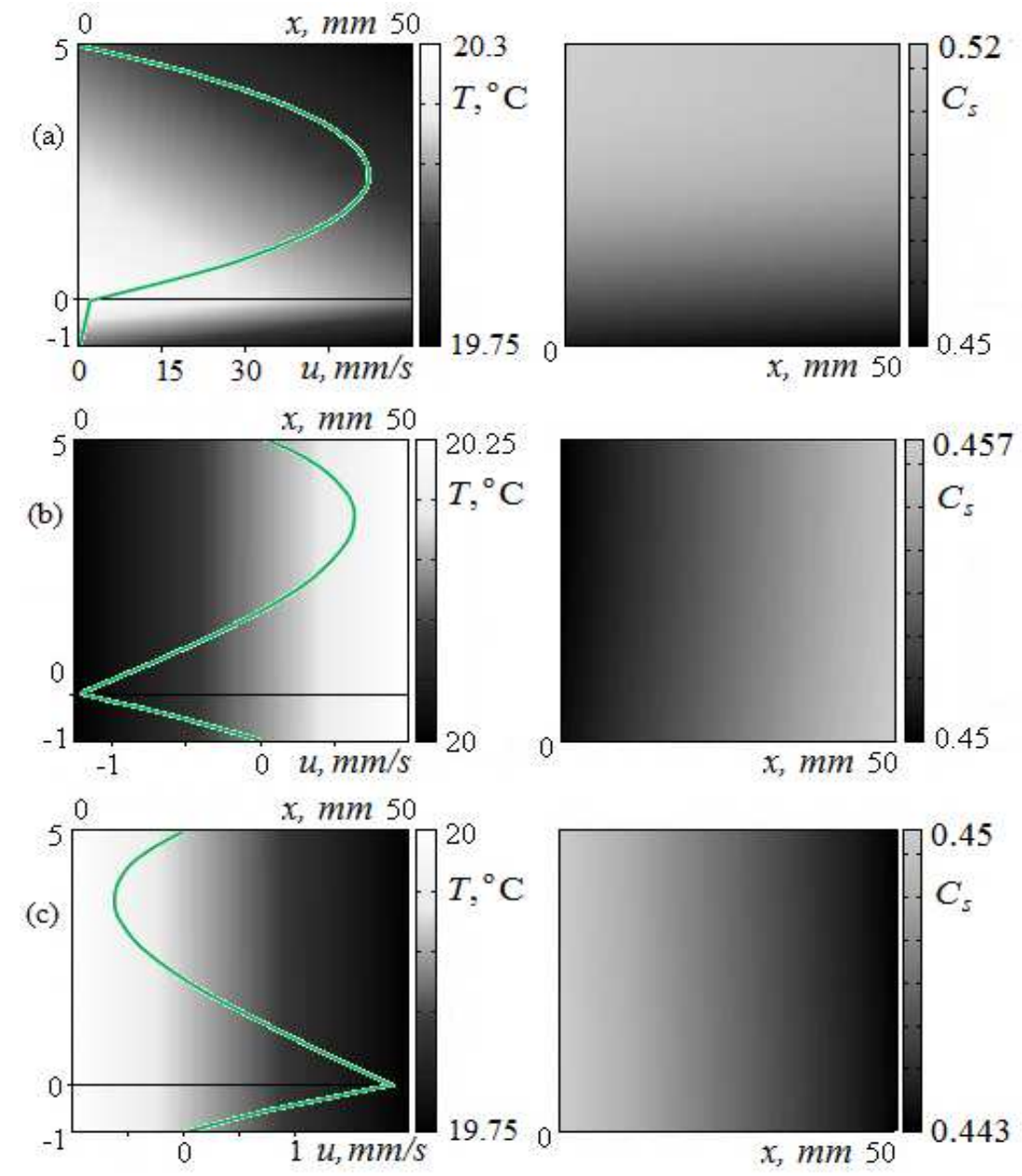

Figure 3. Distributions of the velocity (solid line), temperature (left) and concentration (right) for Flow $4, h_{1}=1 \mathrm{~mm}, h_{2}=5 \mathrm{~mm}$ : a) $-R=9.6 \cdot 10^{-4} \mathrm{~kg} /(\mathrm{m} \cdot \mathrm{s}), A_{1}=A_{2}=A=$ $\left.-5 \mathrm{~K} / \mathrm{m}, M=-1.328 \cdot 10^{-4} \mathrm{~kg} /\left(\mathrm{m}^{2} \cdot \mathrm{s}\right) ; \mathrm{b}\right)-R=9.6 \cdot 10^{-7} \mathrm{~kg} /(\mathrm{m} \cdot \mathrm{s}), A_{1}=A_{2}=A=5 \mathrm{~K} / \mathrm{m}$, $\left.M=1.328 \cdot 10^{-7} \mathrm{~kg} /\left(\mathrm{m}^{2} \cdot \mathrm{s}\right) ; \mathrm{c}\right)-R=9.6 \cdot 10^{-7} \mathrm{~kg} /(\mathrm{m} \cdot \mathrm{s}), A_{1}=A_{2}=A=-5 \mathrm{~K} / \mathrm{m}$, $M=-1.328 \cdot 10^{-7} \mathrm{~kg} /\left(\mathrm{m}^{2} \cdot \mathrm{s}\right)$.

where Pr, Gr, Ma, Ga Le are the Prandtl, Grashof, Marangoni, Galilei and Lewis numbers, respectively. The sign of the $Q$ parameter defines the character of the thermal load on the channel walls, the values $Q<0$ correspond to cooling of the walls in the direction of the $O x$ axis, and the values $Q>0$ correspond to heating.

The concentration is a non-dimensional function, and the non-dimensional velocity $\mathbf{u}_{j}^{\prime}$, temperature $T_{j}^{\prime}$ and pressure $p_{j}^{\prime}$ are defined as follows:

$$
\mathbf{u}_{j}=\frac{\nu_{2}}{h_{2}} \mathbf{u}_{j}^{\prime}, \quad T_{j}=T_{20} T_{j}^{\prime}, \quad p_{j}=\frac{\rho_{2} \nu_{2}^{2}}{h_{2}^{2}} p_{j}^{\prime} .
$$

The primes will be omitted further. Now equations (1)-(5) have the following form

$$
-h<\xi<0: \quad u_{1 \tau}+u_{1} u_{1 \eta}+v_{1} u_{1 \xi}=-\frac{1}{\rho} p_{1 \eta}+\nu\left(u_{1 \eta \eta}+u_{1 \xi \xi}\right),
$$




$$
\begin{aligned}
& v_{1 \tau}+u_{1} v_{1 \eta}+v_{1} v_{1 \xi}=-\frac{1}{\rho} p_{1 \xi}+\nu\left(v_{1 \eta \eta}+v_{1 \xi \xi}\right)+\beta \mathrm{Gr} T_{1}, \\
& u_{1 \eta}+v_{1 \xi}=0, \\
& T_{1 \tau}+u_{1} T_{1 \eta}+v_{1} T_{1 \xi}=\frac{\chi}{\operatorname{Pr}}\left(T_{1 \eta \eta}+T_{1 \xi \xi}\right), \\
& 0<\xi<1: \quad u_{2 \tau}+u_{2} u_{2 \eta}+v_{2} u_{2 \xi}=-p_{2 \eta}+u_{2 \eta \eta}+u_{2 \xi \xi}, \\
& v_{2 \tau}+u_{2} v_{2 \eta}+v_{2} v_{2 \xi}=-p_{2 \xi}+v_{2 \eta \eta}+v_{2 \xi \xi}+\mathrm{Gr}_{2}+\gamma \mathrm{Ga} C_{s}, \\
& u_{2 \eta}+v_{2 \xi}=0, \\
& T_{2 \tau}+u_{2} T_{2 \eta}+v_{2} T_{2 \xi}=\frac{1}{\operatorname{Pr}}\left[T_{2 \eta \eta}+T_{2 \xi \xi}+\frac{\delta}{T_{20}}\left(C_{s \eta \eta}+C_{s \xi \xi}\right)\right], \\
& C_{s \tau}+u_{2} C_{s \eta}+v_{2} C_{s \xi}=\frac{\operatorname{Le}}{\operatorname{Pr}}\left(C_{s \eta \eta}+C_{s \xi \xi}\right) .
\end{aligned}
$$

Conditions $(8)-(10)$ on the boundaries $\xi=-h, \xi=1$ are the following

$$
\begin{gathered}
u_{1}(-h)=0, \quad u_{2}(1)=0, \quad C_{s \xi}(1)=0, \\
T_{1}(\eta,-h)=\frac{A_{1}}{A_{2}} \mathrm{Q} \eta+\frac{T_{10}}{T_{20}}, \quad T_{2}(\eta, 1)=\mathrm{Q} \eta+1 .
\end{gathered}
$$

On the interface $\xi=0$ conditions $(12)-(16)$ are rewritten as follows

$$
\begin{gathered}
u_{1}=u_{2}, \quad T_{1}=T_{2}, \quad p_{1}=p_{2}, \quad \rho \nu u_{1 \xi}=u_{2 \xi}+\frac{\mathrm{Ma}}{\mathrm{Q}} T_{\eta}, \\
k T_{1 \xi}-T_{2 \xi}-\left.\frac{\delta}{T_{20}} C_{s \xi}\right|_{\xi=0}=\left.\frac{D L \rho_{2}}{k_{2} T_{20}} C_{s \xi}\right|_{\xi=0}, \\
\left.C_{s}\right|_{\xi=0}=C_{*}\left[1+\varepsilon T_{20}\left(\left.T_{2}\right|_{\xi=0}-T_{0}^{\prime}\right)\right] .
\end{gathered}
$$

The gas flow rate in the upper layer (17) is rewritten

$$
\int_{0}^{1} u_{2}(\xi) d \xi=\mathrm{Re}
$$

where the non-dimensional parameter $\operatorname{Re}=R /\left(\rho_{2} \nu_{2}\right)$ is the flow rate's Reynolds number.

\section{Stability problem}

\subsection{Linearized equations}

Let us introduce new unknown functions

$$
\left(\widehat{\mathbf{U}}_{j}, \widehat{P}_{j}, \widehat{T}_{j}, \widehat{C}\right)=\left(\mathbf{u}_{j}, p_{j}, T_{j}, C_{s}\right)+\left(\mathbf{U}_{j}, P_{j}, \Theta_{j}, C\right),
$$

where $\mathbf{u}_{j}, p_{j}, T_{j}, C_{s}$ are the solutions (6), $\mathbf{U}_{j}=\left(V_{j}, W_{j}\right), P_{j}=P_{j}(\tau, \eta, \xi), \Theta_{j}=$ $=\Theta_{j}(\tau, \eta, \xi), C=C(\tau, \eta, \xi)$ are the small perturbations of velocity, pressure, temperature and concentration, respectively. 
We consider the problem with condition (10) for the vapor concentration. Under the assumption that function (25) is the solution of the boundary problem $(20)-(24)$, the linearization of equations (20), (21) near the stationary solution (7) results in the system of equations for small disturbances (see, for example, (Lin 1955, Landau and Lifshitz 1959, Betchov and Criminale 1967, Drazin and Reid 1981)). In the general case, when $a_{2}^{1}, a_{2}^{2} \neq 0$, the derivatives of the known functions (6) depending on $\eta$ and $\xi$ are included in the above mentioned system of equations. In this case the normal mode analysis is not applicable and the investigation of the solution stability is reduced to the numerical solving the spatial-temporal problem in terms of "stream function-vorticity".

Let us introduce the functions $(\omega, \Omega)$ and $(\psi, \Psi)$ as usual:

$$
\begin{gathered}
(u, U)=\frac{\partial(\psi, \Psi)}{\partial \xi}, \quad(v, V)=(0, V)=-\frac{\partial(\psi, \Psi)}{\partial \eta}, \\
(\omega, \Omega)=\left(v_{\eta}-u_{\xi}, V_{\eta}-U_{\xi}\right)=\left(0-u_{\xi}, V_{\eta}-U_{\xi}\right)=\left(-u_{\xi}, V_{\eta}-U_{\xi}\right),
\end{gathered}
$$

where $\Psi$ and $\Omega$ are the perturbations of the stream function and vorticity, correspondingly.

In view of the solution type, $\psi$ does not depend on $\eta, \psi=\psi(\xi)$ and $\omega=-u_{\xi}$. Then, the basic system has the following form:

$$
\begin{aligned}
& \Omega_{1 \tau}+\frac{\partial \psi_{1}}{\partial \xi} \Omega_{1 \eta}-\omega_{1 \xi} \frac{\partial \Psi_{1}}{\partial \eta}=\nu \triangle \Omega_{1}+\beta \mathrm{Gr} \Theta_{1 \eta} \\
& \triangle \Psi_{1}=-\Omega_{1} \\
& \Theta_{1 \tau}+\frac{\partial \psi_{1}}{\partial \xi} \Theta_{1 \eta}+\theta_{1 \eta} \frac{\partial \Psi_{1}}{\partial \xi}-\theta_{1 \xi} \frac{\partial \Psi_{1}}{\partial \eta}=\frac{\chi}{\operatorname{Pr}}\left(\Theta_{1 \eta \eta}+\Theta_{1 \xi \xi}\right) \\
& \Omega_{2 \tau}+\frac{\partial \psi_{2}}{\partial \xi} \Omega_{2 \eta}-\omega_{2 \xi} \frac{\partial \Psi_{2}}{\partial \eta}=\triangle \Omega_{2}+\operatorname{Gr} \Theta_{2 \eta}+\operatorname{Ga} \gamma C_{\eta} \\
& \triangle \Psi_{2}=-\Omega_{2}, \\
& \Theta_{2 \tau}+\frac{\partial \psi_{2}}{\partial \xi} \Theta_{2 \eta}+\theta_{2 \eta} \frac{\partial \Psi_{2}}{\partial \xi}-\theta_{2 \xi} \frac{\partial \Psi_{2}}{\partial \eta}=\frac{1}{\operatorname{Pr}}\left(\left(\Theta_{2 \eta \eta}+\Theta_{2 \xi \xi}\right)+\frac{\delta}{T_{20}}\left(C_{\eta \eta}+C_{\xi \xi}\right)\right) \\
& C_{\tau}+\frac{\partial \psi_{2}}{\partial \xi} C_{\eta}+c_{\eta} \frac{\partial \Psi_{2}}{\partial \xi}-c_{\xi} \frac{\partial \Psi_{2}}{\partial \eta}=\frac{L e}{\operatorname{Pr}}\left(C_{\eta \eta}+C_{\xi \xi}\right)
\end{aligned}
$$

The boundary conditions on the outer walls are the following:

$$
\begin{aligned}
& \left.\frac{\partial \Psi_{1}}{\partial \xi}\right|_{\xi=-h}=-\left.\frac{\partial \Psi_{1}}{\partial \eta}\right|_{\xi=-h}=\left.\Theta_{1}\right|_{\xi=-h}=0, \\
& \left.\frac{\partial \Psi_{2}}{\partial \xi}\right|_{\xi=1}=-\left.\frac{\partial \Psi_{2}}{\partial \eta}\right|_{\xi=1}=\left.\Theta_{2}\right|_{\xi=1}=0, \\
& C_{\xi}(1)=0 .
\end{aligned}
$$

The kinematic condition on $\Gamma(\xi=0)$ guarantees that the following equalities should hold

$$
\Psi_{1 \eta}=\Psi_{2 \eta}=\Psi_{\eta}=0
$$


Furthermore, the following conditions are to be valid at the interface

$$
\left.\frac{\partial \Psi_{1}}{\partial \xi}\right|_{\xi=0}=\left.\frac{\partial \Psi_{2}}{\partial \xi}\right|_{\xi=0}=\Psi_{\xi},\left.\quad \frac{\partial \Psi_{1}}{\partial \eta}\right|_{\xi=0}=\left.\frac{\partial \Psi_{2}}{\partial \eta}\right|_{\xi=0}=\Psi_{\eta}
$$

The first of these conditions implies the equality of the tangential velocity perturbations, and, consequently, the equality of their derivatives with respect to the tangential direction $\eta$. The presented conditions can be rewritten as $\Psi_{1 \xi}=\Psi_{2 \xi}, \Psi_{1}=\Psi_{2}=0$. The first of them will be used below in derivation of the normal part of the dynamic condition in terms of $\Psi$ and $\Omega$ (see (33)). Thus, only conditions

$$
\Psi_{1}=\Psi_{2}=0
$$

remain and will be used directly.

The conditions of the energy balance and continuity of the temperature field lead to

$$
k \Theta_{1 \xi}-\Theta_{2 \xi}-\frac{\delta}{T_{20}} C_{\xi}=0, \quad \Theta_{1}=\Theta_{2} .
$$

Due to the form of the solution $\psi_{j}=\psi_{j}(\xi)$ and $\psi_{j \eta}=0$, and with the help of the equality $\Psi_{1 \xi}=\Psi_{2 \xi}$, the tangential and normal components of the dynamic conditions for perturbations can be written as

$$
\begin{aligned}
& \Omega_{2}-\nu \rho \Omega_{1}=\frac{M a}{Q} \Theta_{\eta}, \\
& \Omega_{2 \xi}-\nu \rho \Omega_{1 \xi}+(1-\rho)\left(\psi_{\xi} \Psi_{\xi \eta}+\Psi_{\xi \tau}\right)+2\left(\nu \rho \Psi_{1 \eta \xi \eta}-\Psi_{2 \eta \xi \eta}\right)=0 .
\end{aligned}
$$

In derivation of the conditions on $\Gamma$ we have assumed that the interface remains to be non-deformed, i.e. the perturbations of the desired functions do not lead to the interface perturbations. Let us note that the most problems with interface are characterized by small values of the Crispation number $\mathrm{Cr}=\rho \nu \chi / \sigma_{T} h$ (in studied case $\left.\mathrm{Cr}=4 \cdot 10^{-5}\right)$. A procedure of a expansion in powers of $\mathrm{Cr}$, was presented in the review (Puknachov 1989). We suppose that in the first approximation the interface is the interface of capillary equilibrium. The questions related with interface correction can be solved, for instance, according to (Zebib A. et al. 1985, Myshkis et al 1987, Andreev et al 2000).

For numerical calculations the finite region with respect to the $\eta$ and $\xi$ directions is necessary. Let us limit the computational domain on $\eta$ by length $-l^{\prime} \leq \eta \leq l^{\prime}$. Thus, we suppose the flow domain is limited on the left and right sides with respect to the longitudinal axis by fully permeable undeformed walls. Then, the basic solution is interpreted to be the one describing the flow on the working section. It is necessary to have such a length of the section so that we could observe perturbations with the wavelength being shorter than the section length. It is known from the normal wave analysis that the wavelength of the disturbances, leading to instability, is smaller than $2 \pi$. Taking into account the accepted non-dimensionalization we have $l \geq 2 \pi h_{2}$. Thus, it is sufficient to choose the computational domain with $l=10 \pi h_{2}$ in the dimensional variables and with $l^{\prime}=10 \pi$ in the non-dimensional ones. 
The boundary conditions for the perturbations on $\eta=-l^{\prime}$ and $\eta=l^{\prime}$ are

$$
\begin{aligned}
& \Psi_{1 \eta}=\Psi_{2 \eta}=0, \\
& \Psi_{1}=\Psi_{2}=0, \quad \Theta_{1}=\Theta_{2}=0, \quad C=0 .
\end{aligned}
$$

Condition (34) is imposed by the form of the exact solution $\left(v=-\psi_{\eta}=0\right)$. Conditions (35) mean that the perturbations fade out on the boundaries of the working area and influence the flow properties inside the computational domain only.

The evolution of the perturbations is investigated on the basis of the systems of equations (26), (27) for the non-stationary perturbations periodical with respect to the longitudinal coordinate, which are proportional to $\exp (i q \eta)$. Here, $q$ is the quasiwavenumber of the perturbations (Ziman 1972).

Taking into account the last assumption the following initial conditions are added to the obtained system:

$$
\begin{aligned}
& \Psi_{j \xi}(0, \eta, \xi)=\Psi_{j \xi}^{0}(\eta, \xi)= \pm \gamma_{j}^{u} \bar{\psi}_{j \xi} \cdot \exp (i q \eta), \\
& \Psi_{j \eta}(0, \eta, \xi)=\Psi_{j \eta}^{0}(\eta, \xi)= \pm \gamma_{j}^{v} \bar{\psi}_{j \eta} \cdot \exp (i q \eta), \\
& \Omega_{j}(0, \eta, \xi)=\Omega_{j}^{0}(\eta, \xi)= \pm \gamma_{j}^{\omega} \bar{\omega}_{j} \cdot \exp (i q \eta), \\
& \Theta_{j}(0, \eta, \xi)=\Theta_{j}^{0}(\eta, \xi)= \pm \gamma_{j}^{T} \bar{T}_{j} \cdot \exp (i q \eta), \\
& C(0, \eta, \xi)=C^{0}(\eta, \xi)= \pm \gamma_{j}^{c} \bar{C}_{s} \cdot \exp (i q \eta),
\end{aligned}
$$

where overlined notations are the averaged magnitudes, which are defined as follows

$$
\begin{gathered}
\bar{f}_{j}=\frac{1}{2 h l^{\prime}} \int_{-h}^{0} \int_{-l^{\prime}}^{l^{\prime}} f(\eta, \xi) d \xi d \eta, \quad \text { if } j=1, \\
\bar{f}_{j}=\frac{1}{2 l^{\prime}} \int_{0}^{1} \int_{-l^{\prime}}^{l^{\prime}} f(\eta, \xi) d \xi d \eta, \quad \text { if } j=2,
\end{gathered}
$$

for each characteristic $f$ of the basic flow. The quantities $\gamma_{j}^{u}, \gamma_{j}^{v}, \gamma_{j}^{\omega}, \gamma_{j}^{T}, \gamma_{j}^{c}$ are the components of the corresponding vector $\gamma_{j}$ and $\gamma_{1}^{c} \equiv 0$. The behavior of perturbations in time depends on relations among these components. Furthermore, the relations among these components are defined by governing equations and boundary conditions. The corresponding relationships can be found as a result of substitution of the initial conditions (36) into the problem (26)-(35). Each component of $\boldsymbol{\gamma}_{j}$ can have such values that the amplitudes of the harmonics (36) do not exceed $10 \%$ from the magnitude of the corresponding characteristic of the basic flow $\psi, \omega, T, C_{s}$.

Additionally, let us describe a way of computation of the terms of the equation $\triangle \Psi_{j}=-\Omega_{j}$. Having the exact expressions for the velocity components in the terms of the variables $(u, v)$ we postulate that the initial values $\Psi_{j \xi \xi}^{0}$ and $\Psi_{j \eta \eta}^{0}$ are computed as $\Psi_{j \xi \xi}^{0}= \pm \gamma_{j}^{u} \bar{\psi}_{j \xi \xi} \cdot \exp (i q \eta)$ and $\Psi_{j \eta \eta}^{0}= \pm \gamma_{j}^{u} \bar{\psi}_{j \eta \eta} \cdot \exp (i q \eta)$, where the averaged values $\bar{\psi}_{j \xi \xi}$ and $\bar{\psi}_{j \eta \eta}$ are calculated according to (37). Then the equation $\triangle \Psi_{j}=-\Omega_{j}$ is valid, if the connection $q^{2} \gamma_{j}^{u}=\gamma_{j}^{\omega}$ exists. It should be noted that the use of this way requires 
an additional smoothness of the functions $(u, v)$. The requirement is satisfied for the considered exact solution.

The method of the problem solution (26) - (36) is based on the algorithms suggested in (Goncharova et al 2012b, Vozovoi and Nepomnyashchii 1982).

\section{Possible regimes. Analysis of the results}

For the system HFE-7100 - nitrogen a series of calculations have been performed for the configuration $l_{1}=l_{2}=5 \mathrm{~mm}$ and for different values of the gas flow rate $R$ and gradients $A_{1} \neq A_{2}$.

The computations show that in the system both the monotonic and oscillatory regimes can be formed. These disturbances can damp or grow, depending on $\gamma_{j}$ (which defines the amplitude of the initial perturbations), gas flow rates $R$ and temperature gradients $A_{j}, A$. Depending on the $q$ values, intensity and type of the external action both the thermocapillary (figures 4 and 6) and hydrodynamic (figures 5 and 7) mechanisms can play a dominant role.

In figure 4 the typical distributions of the thermocapillary pattern are presented. The rapid monotonic damping of the perturbations of all the characteristics (velocity, temperature and concentration) is observed even for high amplitudes of the initial perturbations if $R$ and positive $A$ are small. The appearing transversal rolls fade out and the velocity disturbances are localized near $\Gamma$ due to the Marangoni effect. The appearing vortices define entirely the distribution of the concentration perturbations, which generate concentration "rolls" throughout the thickness of the gas phase. With time the perturbations fade out and these "rolls" turn into "spots". The concentration "spots" drift additionally due to the interaction with the basic flow. The analogous transition from the "rolls" into "spots" takes place for the thermal perturbations. So, the thermocapillary effect stabilizes the basic flow at small $R$ and $A>0$.

If the temperature gradients remain quite small but the flow rate increases, then it leads to unstable regimes (figure 5). For each fixed $A$ a critical value of the gas flow rate $R$ at which the perturbations start growing, can be calculated. If $A<0$ or the initial temperature perturbations in the layers have different signs, the instability develops more quickly. If $A<0$, the action of the Marangoni and shear mechanisms is co-directional, resulting in the growth of hydrodynamic perturbations, whereas the thermal and concentration ones damp slowly (figure 5). The most important points in the different modes of the temperature perturbations in the layers are the type of the basic flow and the value of the initial velocity perturbations. Only the flows with the purely thermocapillary profile of the velocity will be stable if $\gamma_{j}^{u}$ and $\gamma_{j}^{v}$ are small. Thus, we can select the dominant mechanism. At quite large $R$ the most dangerous are the hydrodynamic perturbations. The instability has a hydrodynamic pattern, since the thermocapillary forces are suppressed by shear stresses. 

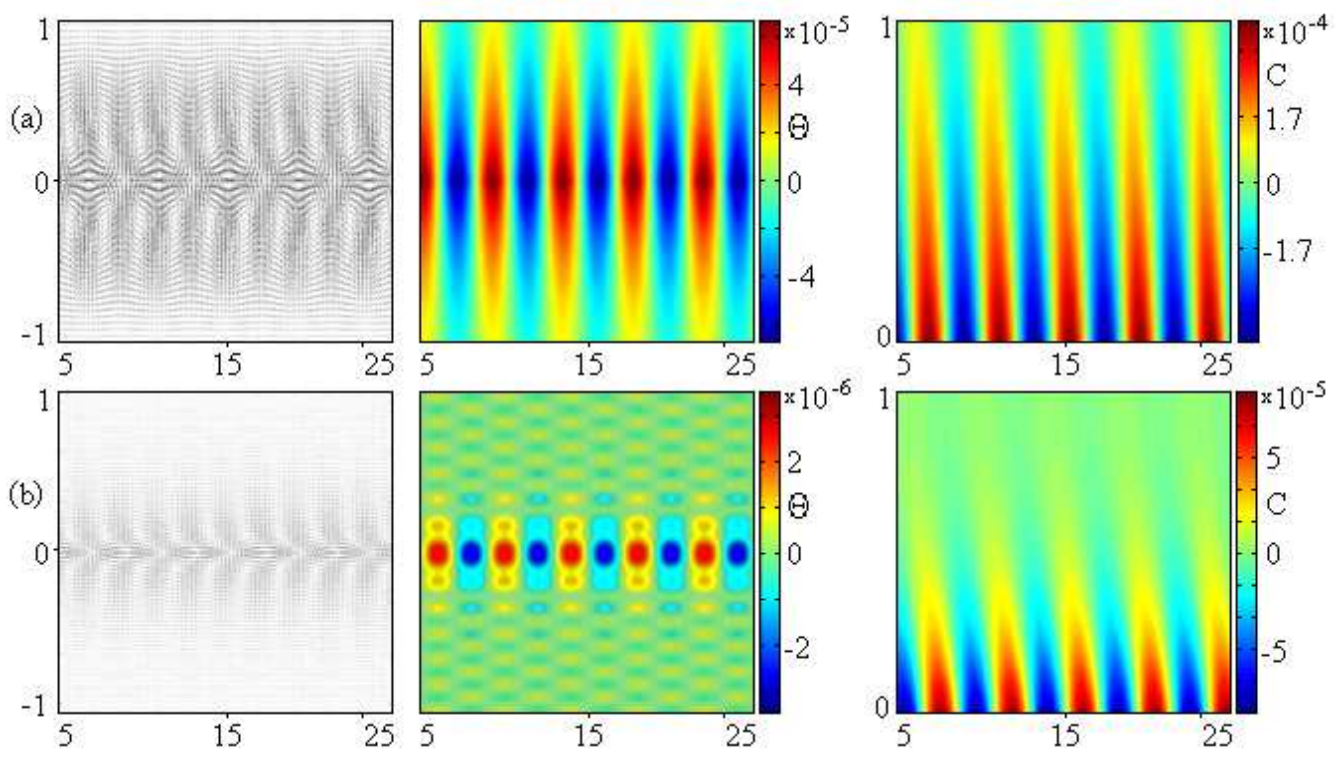

Figure 4. Monotonically damping disturbances of the velocity, temperature and concentration, $R=9.6 \cdot 10^{-6} \mathrm{~kg} /(\mathrm{m} \cdot \mathrm{s}), A_{1}=5 \mathrm{~K} / \mathrm{m}, A=0.8058 \mathrm{~K} / \mathrm{m}, A_{2}=-10 \mathrm{~K} / \mathrm{m}$, $q=5,\left|\gamma_{j}\right|=0.07$ : a) $\left.-t=0.5 \mathrm{~s} ; \mathrm{b}\right)-t=2.5 \mathrm{~s}$.
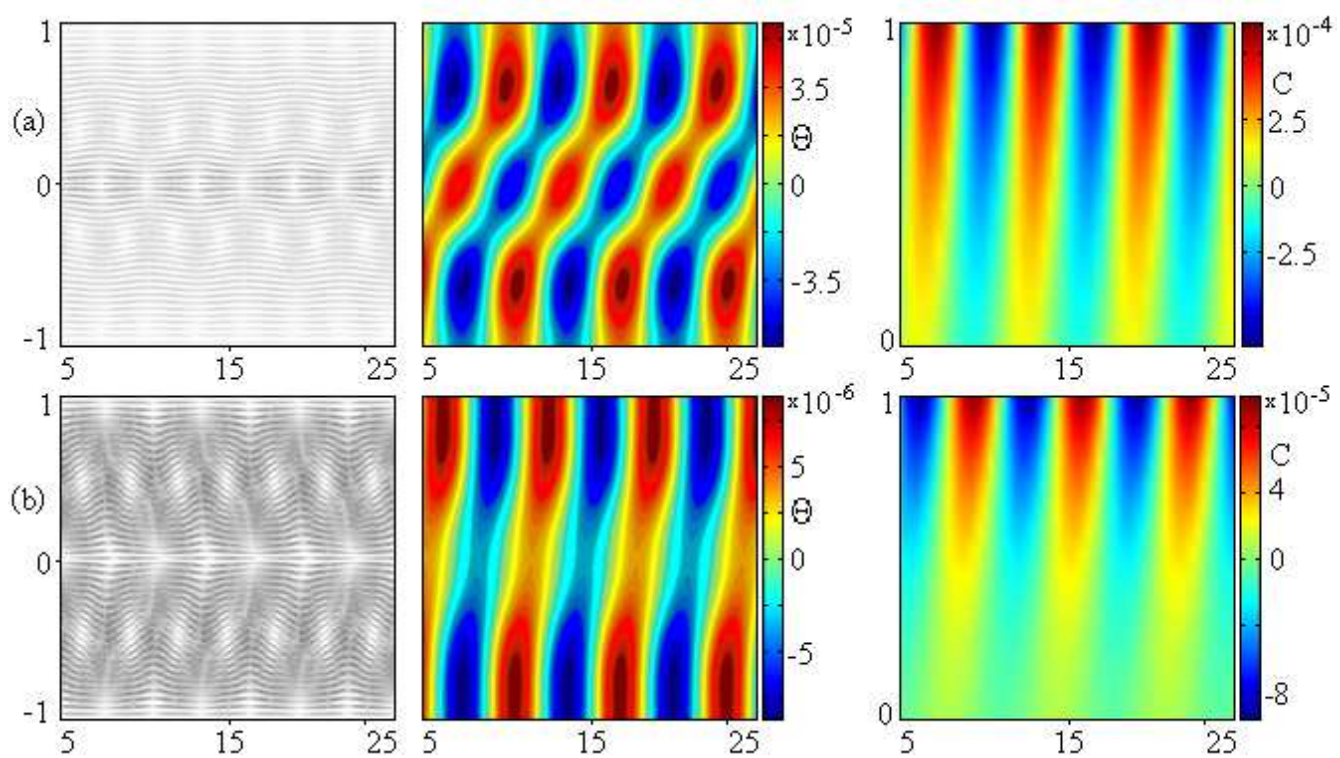

Figure 5. Monotonous instability of hydrodynamic character, growing disturbances of velocity and damping disturbances of temperature and concentration, $R=9.6 \cdot 10^{-4} \mathrm{~kg} /(\mathrm{m} \cdot \mathrm{s})$, $A_{1}=-5 \mathrm{~K} / \mathrm{m}, A=-0.8058 \mathrm{~K} / \mathrm{m}, A_{2}=10 \mathrm{~K} / \mathrm{m}, q=5,\left|\gamma_{j}\right|=0.07:$ a) $\left.-t=0.5 \mathrm{~s} ; \mathrm{b}\right)-$ $t=4 \mathrm{~s}$.

The increasing values of the gradients and gas flow rates lead to the formation of the oscillatory modes (figures 6 and 7). They are caused by the influence of the thermocapillary mechanism and shear stresses. These mechanisms are counteractive. Under the action of the hydrodynamic perturbations the fluid moves in the direction of the main flow, but the thermocapillary mechanism forces the particles to move in the 
opposite direction. By increasing $\left|\boldsymbol{\gamma}_{j}\right|$ the oscillation frequency grows.

Damping or growing of the oscillatory disturbances are controlled by the values of the initial disturbances. At quite small $\left|\boldsymbol{\gamma}_{j}\right|$ the disturbances attenuate, large vortices fade out to the small ones and then, these small vortices are merged back into the large ones, but the sizes of the "pulsating" vortices decrease gradually in the stable regimes (figure 6) and they persist or increase in the unstable ones (figure 7). The field of the concentration perturbations responds also to these oscillations of the vortices.

With the increasing pseudowavenumber $q$ the sizes of the appearing structures change: large-scale structures (vortices and thermal/concentration "rolls") transform into small-scale ones. It should be noted that at large gas flow rates $R$ the increasing $q$ leads to the formation of high-frequency regimes. If $R$ is small, then the increasing $q$ can result in the transition from the hydrodynamic patterns to the thermocapillary ones.

\section{Concluding remarks}

The stationary exact solution of the stationary Oberbeck-Boussinesq equations has been investigated in detail. The solution describes a joint flow liquid and a vapor-gas mixture in a minichannel with solid outer walls. Basic equations take into account the effects of thermodiffusion and diffusive heat conductivity additionally in the gas phase. The considered solution is the analogue of the Ostroumov-Birikh solution of the Oberbeck-Boussinesq equations. The solution has a group nature and describes different classes of flows. A variety of the described types of flows is explained by the properties of the solution (6). Also, the structure of the solution allows one to use different classes of boundary conditions for the vapor concentration function $C_{s}$. The influence of the boundary conditions and considered effects on the properties of the solution and, consequently, on the characteristics of the two-layer flows are clarified based on theoretical analysis. The classification of the flow types has been suggested, depending on the boundary conditions for the $C_{s}$ function and on the given parameters of the problem.

The stability of one of the classes of the obtained solutions has been studied and two different types of instabilities have been found. The behavior of the obtained solutions has been investigated with different values of external actions (gas flow rates $R$ and longitudinal temperature gradients $\left.A_{j}, A\right)$. The stability of the basic Flow 4 is guaranteed only if the values are small.

The suggested approach to study the influence of different mechanisms and generation of the convective and concentration structures requires further development since the obtained results can predict only some qualitative and quantitative features of the joint flows of the evaporating fluid and co-current gas flux. Additional factors such 

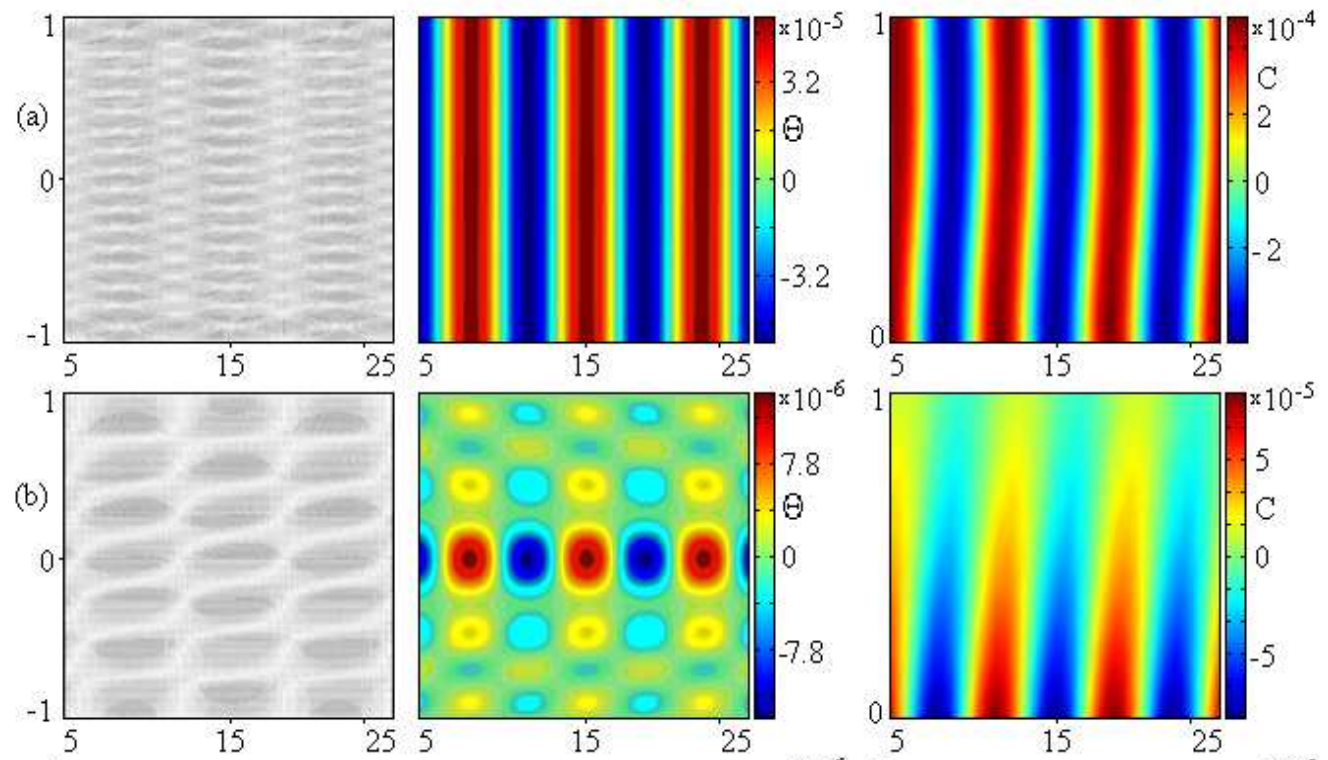

(c)
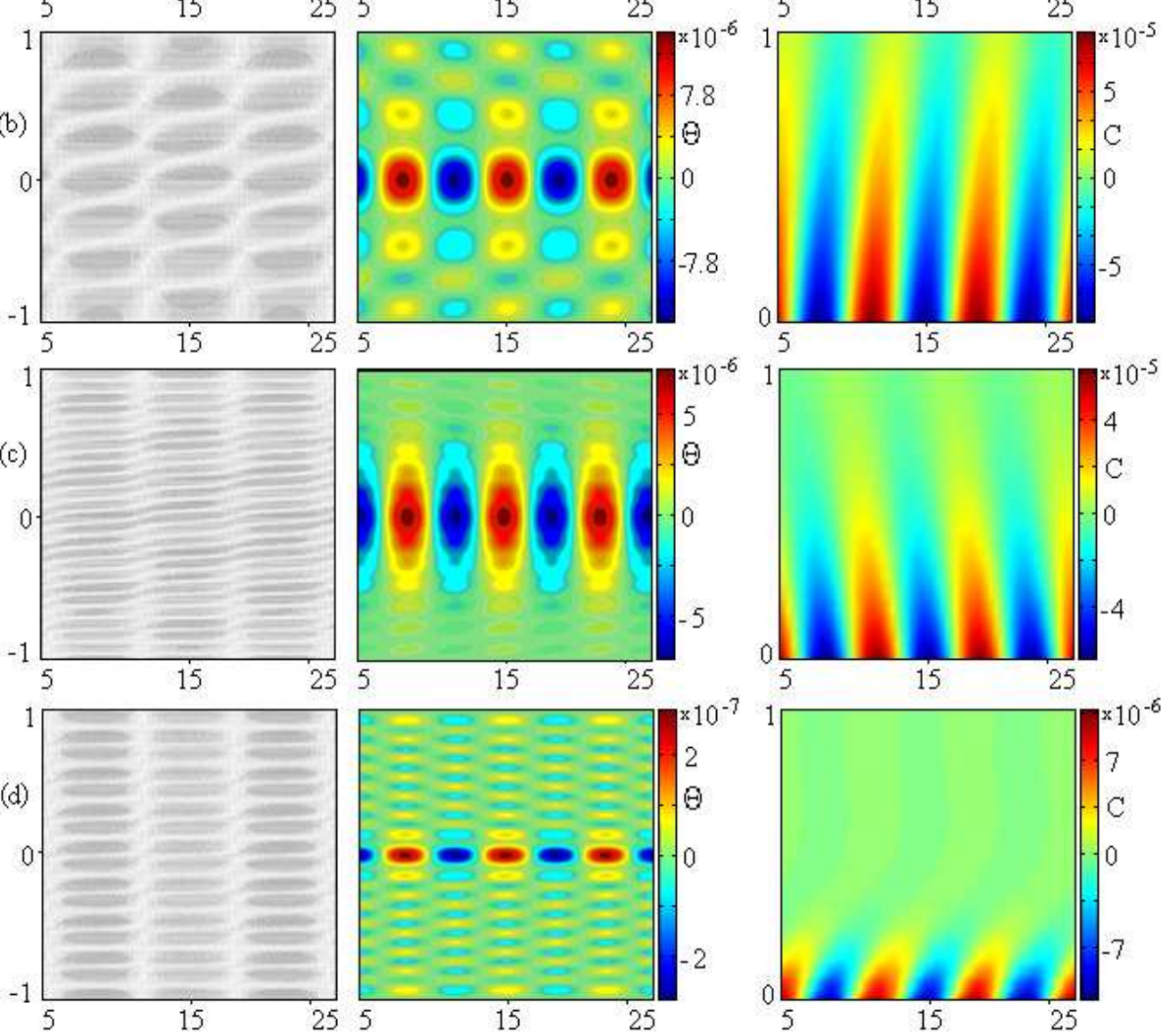

Figure 6. Damping oscillatory disturbances of The velocity, temperature and concentration, $R=9.6 \cdot 10^{-5} \mathrm{~kg} /(\mathrm{m} \cdot \mathrm{s}), A_{1}=50 \mathrm{~K} / \mathrm{m}, A=44.407 \mathrm{~K} / \mathrm{m}, A_{2}=30 \mathrm{~K} / \mathrm{m}, q=5,\left|\gamma_{j}\right|=0.02$ : a) $-t=0.5 \mathrm{~s} ; \mathrm{b})-t=1.5 \mathrm{~s}$; c) $t=3 \mathrm{~s}, \mathrm{~d}) t=5 \mathrm{~s}$.

as thermophysical properties of the working media, linear sizes of the system should be taken into account when further considering the problem. Furthermore, the critical characteristics of the stability and influence of the problem parameters require a more detailed study and specification.

\section{Acknowledgments}

This work was financially supported by the Russian Foundation for Basic Research (project No. 14-08-00163). The authors gratefully acknowledge the above-mentioned sponsorship. The first author also acknowledges the Government of the Russian 

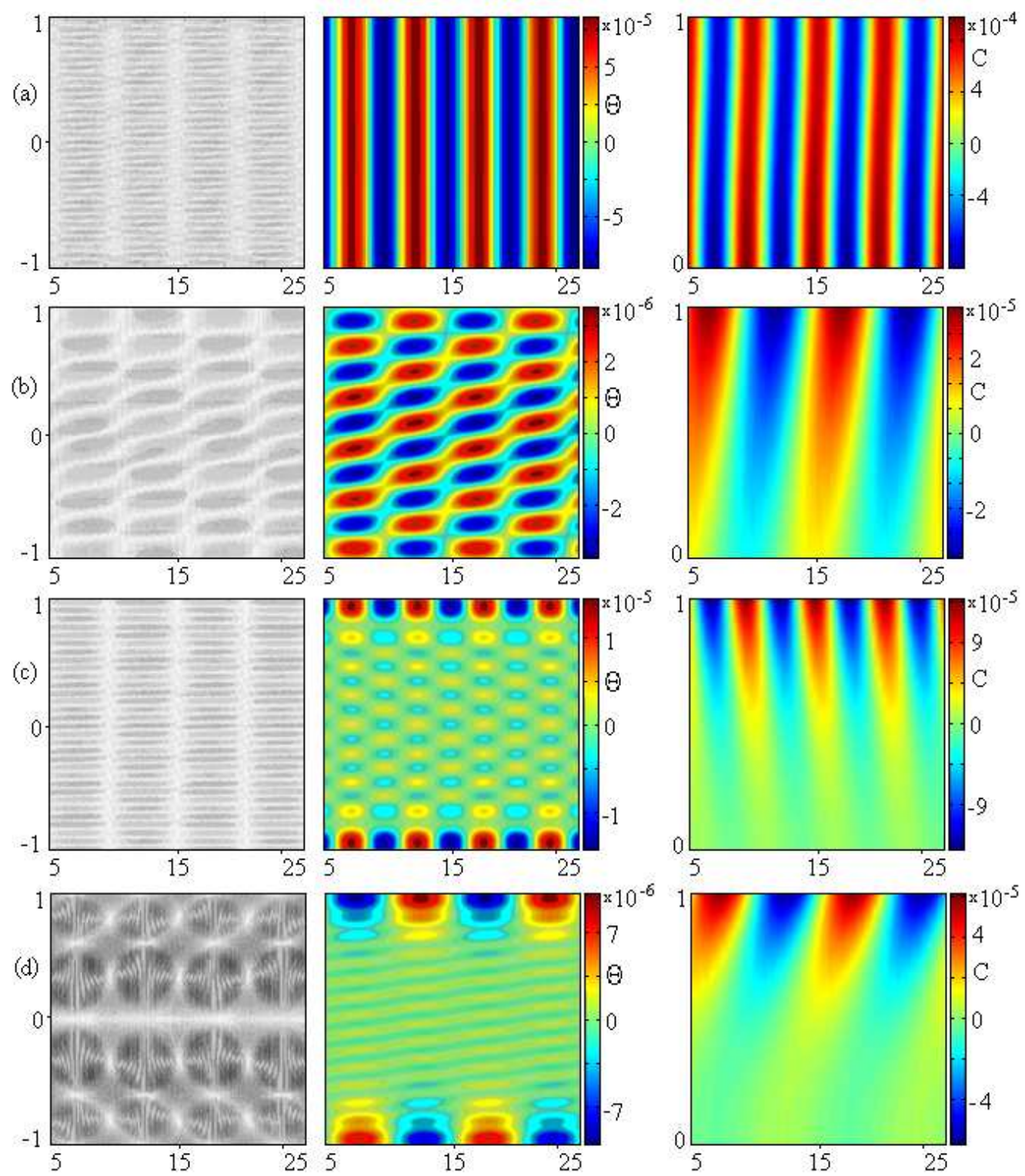

Figure 7. Oscillatory instability, growing disturbances of velocity and damping disturbances of temperature and concentration, $R=2.4 \cdot 10^{-4} \mathrm{~kg} /(\mathrm{m} \cdot \mathrm{s}), A_{1}=-20 \mathrm{~K} / \mathrm{m}, A=-0.4272 \mathrm{~K} / \mathrm{m}$, $\left.\left.\left.\left.A_{2}=50 \mathrm{~K} / \mathrm{m}, q=3,\left|\gamma_{j}\right|=0.08: \mathrm{a}\right)-t=0.5 \mathrm{~s} ; \mathrm{b}\right)-t=1.5 \mathrm{~s} ; \mathrm{c}\right) t=5 \mathrm{~s}, \mathrm{~d}\right) t=9 \mathrm{~s}$.

Federation, for partial support, grant for studying under the supervision of leading scientists in the Siberian Federal University (project No. 14.Y26.31.0006).

\section{References}

Andreev V.K. and Bekezhanova V.B. 2010 Stability of Nonisothermal Fluids, (Siberian Federal University, Krasnoyarsk) (in Russian)

Andreev V.K., Gaponenko Yu.A., Goncharova O.N. and Pukhnachev V.V. 2012 Mathematical Models of Convection (Walter de Gruyter GmbH \& CO KG, Berlin/Boston)

Andreev V.K. and Sobachkina N.L. 2012 Motion of binary mixture in plane and cylindrical domains (Siberian Federal University, Krasnoyarsk) (in Russian) 
Andreev V.K., Zakhvataev V.E., Ryabitskii E.A. 2000 Thermocapillary instability (Nauka, Novosibirsk) (in Russian)

Betchov R., Criminale W.O. 1967 Stability of parallel flows (Academic, New York)

Birikh R.V. 1966 Thermocapillary convection in a horizontal layer of liquid, J. Appl. Mech. Tech. Phys., $7(3), 43-44$

Burelbach J.P., Banko S.G., Davis S.H. 1988 Nonlinear stability of evaporating/condensing films J. Fluid Mech., 195, 463-494

Celata G.P., Colin C., Colinet P., Di Marco P., Gambaryan-Roisman T., Kabov O.A., Kyriopoulos O., Stephan P., Tadris, L., Tropea C. 2008 Bubbles, drops, films: transferring heat in space Europhysics News, 39(4), 23-25

Das K.S. and Ward C.A. 2007 Surface thermal capacity and its effects on the boundary conditions at fluid-fluid interfaces Phys. Rev. E, 75(6), 065303(R)

De Groot S.R. 1951 Thermodynamics of irreversible processes (North-Holland publishing Co., Amsterdam; Interscience Puhlishers, Inc., New York)

De Groot S.R., Mazur P. 1962 Non-equilibrium thermodynamics, 2nd edn. (NorthHolland, Amsterdam)

Drazin P.G., Reid W.H. 1981 Hydrodynamic stability (Cambridge University Press, Cambridge)

Frezzotti A. 2011 Boundary conditions at the vapor-liquid interface Phys. Fluids, 23, 030609

Gatapova E.Ya., Kabov O.A. 2008 Shear-driven flows of locally heated liquid films Int. J. Heat Mass Transfer, 51(19-20), 4797-4810

Gebhart B., Jaluria Y., Mahajan R.L., Sammakia B. 1988 Bouyancy-induced flows and transport (Springer Verlag, Berlin-Heidelberg-New York-London-Paris-Tokyo)

Ghezzehei T.A., Trautz R.C., Finsterle S., Cook, P.J., Ahlers, C.F. 2004 Modeling coupled evaporation and seepage in ventilated cavities Vadose Zone J., 3(3), 806-818

Goncharova O.N. 2012a Modeling of flows under conditions of heat- and mass transfer at the interface Izvestiya Altaiskogo gosudarstvennogo univ., 73(1/2), 12-18 (in Russian)

Goncharova O.N. 2015a Two-layer fluid flows with evaporation at an interface in the presence of an anomalous thermocapillary effect Izvestiya Altaiskogo gosudarstvennogo universiteta, 85(1/2), 101105 (in Russian)

Goncharova O.N., Hennenberg M., Rezanova E.V., Kabov O.A. 2013 Modeling of the convective fluid flows with evaporation in the two-layer systems Interfacial phenomena and heat transfer, 1(3), $317-338$

Goncharova .N., Kabov O.A, Pukhnachov V.V. 2012b Solutions of special type describing the three dimensional thermocapillary flows with an interface Int. J. Heat and Mass Transfer, 55, 715-725

Goncharova O.N., Lyulin Yu.V., Rezanova E.V., Kabov O.A. 2015b Modeling of the stationary problem of two-layer flows of the liquid and gas by evaporation Thermophysics and Aeromechanics, 22(5), $655-661$

Goncharova O.N., Rezanova E.V. 2014a Mathematical model of the flows of a thin liquid layer subject to evaporation on the thermocapillary interface Izvestiya Altaiskogo gosudarstvennogo univ., 81(1/2), 21-25 (in Russian)

Goncharova O.N., Rezanova E.V. 2014b Example of an exact solution of the stationary problem of two-layer flows with evaporation at the interface J. Appl. Mech. Tech. Phys., 55(2), 247-257

Goncharova O.N., Rezanova E.V. 2015c Construction of a mathematical model of flows in a thin liquid layer on the basis of the classical convection equations and generalized conditions on an interface Izvestiya Altaiskogo gosudarstvennogo univ., 85(1/1), 70-74 (in Russian)

Goncharova O.N., Rezanova E.V., Lyulin Yu.V., Kabov O.A. 2016 Study of the convective flows of the liquid and co-current gas flux with evaporation High Temperature (accepted for publication)

Goncharova O.N., Rezanova E.V., Tarasov Ya.A. 2014c Mathematical modeling of the thermocapillary fluid flows in a thin layer with evaporation Izvestiya Altaiskogo gosudarstvennogo univ., 81(1/1), 47-52 (in Russian)

Haut B., Colinet P. 2005 Surface-tension-driven instability of a liquid layer evaporating into an inert gas J. Colloid and Interface Science, 285, 296-305 
Iorio C.S. Goncharova O.N., Kabov O.A. 2009 Study of evaporative convection in an open cavity under shear stress flow Microgravity Sci. Technol., 21(1), 313-320

Iorio C.S. Goncharova O.N., Kabov O.A. 2011 Heat and mass transfer control by evaporative thermal pattering of thin liquid layers Computational Thermal Sci., 3(4), 333-342

Iorio C. S., Kabov O. A., Legros J. C. 2007 Thermal Patterns in evaporating liquid Microgravity Sci. Technol. 19(3/4), 27-29

Kabova Yu., Kuznetsov V.V., Kabov O., Gambaryan-Roisman T., Stephan P. 2014 Evaporation of a thin viscous liquid film sheared by gas in a microchannel Int. J. Heat Mass Transfer, 68, 527-541

Klentzman J., Ajaev V.S. 2009 The effect of evaporation on fingering instabilities Phys. Fluids, 21, 122101

Kurdyashkin A.G., Polezhaev V.I., Fedyushkin A.I. 1983 Thermal convection in a horizontal layer with lateral heating J. Appl. Mech. Tech. Phys., 24(6), 876-882

Kuznetsov V.V. 2010 Heat and mass transfer at the liquid-gas interface under diffusion evaporation Journal of Siberian Federal. Mathematics and Physics, 3(2), 216-227

Kuznetsov V.V. and Andreev V.K. 2012a Liquid film and gas flow motion in a microchannel with evaporation Thermophysics and Aeromechanics, 20(1), 17-28

Kuznetsov V.V. 2011 Heat and mass transfer on a liquid-vapor interface Fluid Dynamics, 46(5), 754-763

Landau L.D., Lifshitz E.M. 1959 Fluid mechanics (Pergamon, Oxford)

Lin C.-C. 1955 The Theory of Hydrodynamic Stability (Cambridge University Press)

Liu R., Kabov O.A. 2012 Instabilities in a horizontal liquid layer in co-current gas flow with an evaporating interface Physical Review E-Statistical, Nonlinear, and Soft Matter Physics, 85(6), 066305

Lyulin Yu. V., Feoktistov D. V., Afanas'ev I. A., Chachilo E. S., Kabov O. A., Kuznetsov G. V. 2015 Measuring the rate of local evaporation from the liquid surface under the action of gas flow Technical Physics Letters, 41(7), 665-667

Lyulin Y., Kabov O. 2013 Measurement of the evaporation mass flow rate in a horizontal liquid layer partly opened into flowing gas Technical Physics Letters, 39(9), 795-797

Lyulin Y. and Kabov O. 2014 Evaporative convection in a horizontal liquid layer under shear-stress gas flow Int. J. Heat Mass Transfer, 70, 599-609

Maciev L.F., Stasenko A.L. 1987 Evaporation of a drop in the strongly superheated binary mixture Izvestiya AN SSSR. Energetika i transport, 1, 112-118 (in Russian)

Maciev L.F., Ruabinina T.N., Stasenko A.L. 1987 Evaporation of a drop in a heat two-component jet with respect to the thermodiffusion and cross-cutting effect Modeling in mechanics, 1(18), 6, 106-114 (in Russian)

Margerit J., Colinet. P., Lebon G., Iorio C.S., Legros J.C. 2003 Interfacial nonequilibrium and BenardMarangoni instability of a liquid-vapor system Phys. Rev. E, 68, 041601.

Maxwell J.C. 1890 Collected Scientific Papers, Vol. II (Cambridge)

Mialdun A., Shevtsova V. 2011 Digital interferometry as a powerful tool to study the thermodiffusion effect Comptes Rendus Mechanique, 339, 362-368

Myshkis A.D., Babskii V.G., Kopachevskii N.D., Slobozhanin L.A., Tyuptsov A.D. 1987 Low-Gravity Fluid Mechanics (Springer Verlag, Berlin, Heidelbery, New York, London, Paris, Tokio)

Nakoryakov V.E., Bufetov N.S., Grigor'eva N.I., Dekhtyar R.A. 2003 Heat and Mass Transfer During Vapor Absorption by a Stagnant Solution Layer J. Appl. Mech. Tech. Phys., 44(2), 236-242

Napolitano L.G. 1980 Plane Marangoni-Poiseuille flow two immiscible fluids Acta Astronautica, 7, $461-478$

Oron A., Davis S.H., Bankoff S.C. 1997 Long-scale evolution of thin liquid films Reviews of Modern Phys., 69(3), 931-980

Oron A. 2000 Nonlinear dynamics of irradiated thin volatile liquid films Phys. Fluids, 12(1), 29

Ostroumov G.A. 1952 Free Convection under the Conditions of an Internal Problem (Moscow, Gostekhizdat) (in Russian)

Prosperetti A. 1979 Boundary conditions at a liquid-vapor interface Mechanica, 14(1), 34-47 
Pukhnachev V.V. 2000 Group nature of the Birikh solution and its generalizations Proceedings of Int. Conference "Symmetry and differential equations", (Institute of Computational Modelling SB RAS, Krasnoyarsk) (in Russian)

Puknachov V.V. 1989 Thermocapillary convection under low gravity Fluid Dynamics Transactions, 14, $140-204$

Putilov K.A. 1963 Physics course. Vol. 1, (Gos. izdatelstvo fiz.-mat. literatury, Moscow) (in Russian)

Ryzhkov I.I. 2013 Thermodiffusion in mixtures: equations, symmetries, solutions and its stability (Izdatelstvo SB RAS, Novosibirsk) (in Russian)

Sanochkin Yu.V. 1989 Thermocapillary motion of a liquid J. Appl. Mech. Tech. Phys., 30(5), 750-754.

Shklyaev O.E., Fried E. 2007 Stability of an evaporating thin liquid film J. Fluid Mech., 584, 157-183

Shliomis M.I., Yakushin V.I. 1972 Convection in a two-layers binary system with an evaporation Collected papers: Uchenye zapiski Permskogo Gosuniversiteta, seriya Gidrodinamika, 4, 129-140 (in Russian)

Sivukhin D.V. 2005 General physics course. Vol. 2, (Fizmatlit, Moscow) (in Russian)

Sultan E., Boudaoud A., Amat M.B. 2005 Evaporation of a thin film: diffusion of the vapour and Marangoni instabilities J. Fluid Mech, 543, 183-202

Umov N.A. 1950 Selected works, (Gos. izdatelstvo tekhniko-teoreticheskoi literatury, Moscow) (in Russian)

Vozovoi L.P. and Nepomnyashchii A.A. 1982 Stability of stationary spatially periodic convective motions in a plane vertical layer, J. Appl. Mech. Tech. Phys., 23(4), 512-517

Zebib A., Homsy G.M., and Meiburg E. 1985 High Marangoni number convection in a square cavity, Phys. Fluids, 28(12), 3467-3476

Ziman J. M. 1972 Principles of Solid State Theory (Cambridge, Cambridge Univ. Press) 